\title{
Development and evaluation of a suite of isotope reference gases for methane in air
}

\author{
Peter Sperlich $^{1,2}$, Nelly A. M. Uitslag ${ }^{1,3}$, Jürgen M. Richter ${ }^{1}$, Michael Rothe ${ }^{1}$, Heike Geilmann ${ }^{1}$, \\ Carina van der Veen ${ }^{4}$, Thomas Röckmann ${ }^{4}$, Thomas Blunier ${ }^{5}$, and Willi A. Brand ${ }^{1}$ \\ ${ }^{1}$ Max Planck Institute for Biogeochemistry (MPI-BGC), Jena, Germany \\ ${ }^{2}$ National Institute of Water and Atmospheric Research (NIWA), Wellington, New Zealand \\ ${ }^{3}$ Centre for Isotope Research (CIO), Energy and Sustainability Research Institute Groningen (ESRIG), \\ University of Groningen, Groningen, the Netherlands \\ ${ }^{4}$ Institute of Marine and Atmospheric Science in Utrecht (IMAU), Utrecht, the Netherlands \\ ${ }^{5}$ Centre for Ice and Climate (CIC), Niels Bohr Institute, University of Copenhagen, Copenhagen, Denmark
}

Correspondence to: Peter Sperlich (peter.sperlich@niwa.co.nz)

Received: 18 January 2016 - Published in Atmos. Meas. Tech. Discuss.: 20 January 2016

Revised: 10 June 2016 - Accepted: 8 July 2016 - Published: 12 August 2016

\begin{abstract}
Measurements from multiple laboratories have to be related to unifying and traceable reference material in order to be comparable. However, such fundamental reference materials are not available for isotope ratios in atmospheric methane, which led to misinterpretations of combined data sets in the past. We developed a method to produce a suite of synthetic $\mathrm{CH}_{4}$-in-air standard gases that can be used to unify methane isotope ratio measurements of laboratories in the atmospheric monitoring community. Therefore, we calibrated a suite of pure methane gases of different methanogenic origin against international referencing materials that define the VSMOW (Vienna Standard Mean Ocean Water) and VPDB (Vienna Pee Dee Belemnite) isotope scales. The isotope ratios of our pure methane gases range between -320 and $+40 \%$ ofor $\delta^{2} \mathrm{H}-\mathrm{CH}_{4}$ and between -70 and $-40 \%$ for $\delta^{13} \mathrm{C}-\mathrm{CH}_{4}$, enveloping the isotope ratios of tropospheric methane (about -85 and $-47 \%$ for $\delta^{2} \mathrm{H}-\mathrm{CH}_{4}$ and $\delta^{13} \mathrm{C}-\mathrm{CH}_{4}$ respectively). Estimated uncertainties, including the full traceability chain, are $<1.5 \%$ and $<0.2 \%$ ofor $\delta^{2} \mathrm{H}$ and $\delta^{13} \mathrm{C}$ calibrations respectively. Aliquots of the calibrated pure methane gases have been diluted with methane-free air to atmospheric methane levels and filled into $5 \mathrm{~L}$ glass flasks. The synthetic $\mathrm{CH}_{4}$-in-air standards comprise atmospheric oxygen/nitrogen ratios as well as argon, krypton and nitrous oxide mole fractions to prevent gasspecific measurement artefacts. The resulting synthetic $\mathrm{CH}_{4}$ in-air standards are referred to as JRAS-M16 (Jena Reference
\end{abstract}

Air Set - Methane 2016) and will be available to the atmospheric monitoring community. JRAS-M16 may be used as unifying isotope scale anchor for isotope ratio measurements in atmospheric methane, so that data sets can be merged into a consistent global data frame.

\section{Introduction}

Isotope ratios of $\mathrm{CH}_{4}$ in the present and the past atmosphere (e.g. from ice cores) are a powerful tool to study the biogeochemical processes that cause the variation of $\mathrm{CH}_{4}$ in the atmosphere (Stevens and Rust, 1982; Quay et al., 1991, 1999; Lowe et al., 1994; Sapart et al., 2012; Möller et al., 2013; Sperlich et al., 2015; Schaefer et al., 2016). Recently, two conflicting publications highlighted (i) the interpretative power when data sets from multiple laboratories are combined for spatiotemporal analysis of $\mathrm{CH}_{4}$ isotope ratios (Kai et al., 2011) and (ii) the pitfalls when differences due to laboratory offsets are misinterpreted as spatial variability of $\mathrm{CH}_{4}$ sources (Levin et al., 2012). Levin et al. (2012) identified calibration offsets between three laboratories by comparing their long-term observations in Antarctic background air, where the $\delta^{13} \mathrm{C}$ of $\mathrm{CH}_{4}$ is assumed to be free of spatial gradients. However, this technique is a temporary work-around that excludes the use of data sets from laboratories without a history of observations in Antarctica or a traceable link to 
Antarctic observations. This dilemma could be solved if suitable reference materials (RMs) were available to all laboratories that measure isotope ratios of atmospheric $\mathrm{CH}_{4}$.

Certified reference materials (CRMs) are provided by the IAEA, NIST and others for many analytes. The lack of CRMs for $\mathrm{CH}_{4}$ isotope ratios has long been recognised in the literature, ranging from pioneering papers (e.g. Craig, 1953; Schiegl and Vogel, 1970) to recent publications on analytical systems to measure isotope ratios in atmospheric $\mathrm{CH}_{4}$ (e.g. Sapart et al., 2011; Sperlich et al., 2013; Bock et al., 2014; Tokida et al., 2014; Eyer et al., 2015) as well as papers that present and interpret such data (e.g. Levin et al., 2012; Sapart et al., 2013; Schaefer et al., 2016). In the absence of CRMs for isotope ratios of $\mathrm{CH}_{4}$, many laboratories have developed methods to calibrate purified $\mathrm{CH}_{4}$ against CRMs that were available as a "second-best solution", thereby accepting the shortcoming that those CRMs comprised of different physicochemical properties and are therefore not ideal (IAEA, 2003). For example, $\delta^{13} \mathrm{C}-\mathrm{CH}_{4}$ calibrations were made against NBS 20 (limestone) and NBS 21 (graphite) by Stevens and Rust (1982), against NBS $16\left(\mathrm{CO}_{2}\right)$ and NBS 20 (limestone) by Quay et al. (1991), against IAEA-CO-9 (Barium carbonate) by Lowe et al. (1994), against NBS 19 (limestone) by Quay et al. (1999) and against RM $8563\left(\mathrm{CO}_{2}\right)$ by Sperlich et al. (2012). Dumke et al. (1989) calibrated against the natural gas mixtures NGS 1, NGS 2 and NGS 3, which were not of the highest purity level with 81,53 and $99 \% \mathrm{CH}_{4}$ respectively (e.g. IAEA, 2003; Brand et al., 2014). It is furthermore important to understand the variation of uncertainties of the applied CRMs, ranging from assigned values of $0.00 \%$ (NBS 19 , the only primary measurement standard for VPDB) up to $0.56 \%$ (NGS 2) (Brand et al., 2014). The situation becomes even more complicated because the $\delta^{13} \mathrm{C}$ values of some of the applied CRMs were revised and changed by as much as $0.4 \%$ over time (e.g. NBS 21 ; Brand et al., 2014). As a consequence, this would require the adjustment of dependent $\delta^{13} \mathrm{C}-\mathrm{CH}_{4}$ data. The use of different calibration methods, CRMs and the change of their assigned $\delta^{13} \mathrm{C}$ values have undoubtedly contributed to calibration offsets between laboratories. This fact highlights the importance that applied CRMs and their $\delta^{13} \mathrm{C}$ values are reported in the metadata of the measurement results and that their uncertainty is included in the uncertainty budget of the measurements. Fortunately the situation is more homogenous for $\delta^{2} \mathrm{H}-\mathrm{CH}_{4}$ calibrations, which were only made against CRM waters, such as VSMOW2, SLAP2 or their precursors (e.g. Schiegl and Vogel, 1970; Dumke et al., 1989; Quay et al., 1999; Sperlich et al., 2012). Brand et al. (2014) provide a comprehensive overview on the variation of $\delta^{2} \mathrm{H}-\mathrm{H}_{2} \mathrm{O}$ values and associated uncertainties. Another common method for laboratories to anchor $\mathrm{CH}_{4}$ measurements to the VPDB or VSMOW isotope scales is to get their working standard (WS) calibrated by an external laboratory (e.g. Behrens et al., 2008; Brass and Röckmann, 2010; Bock et al., 2014; Schmitt et al., 2014; Rella et al., 2015; Brand et al., 2016). It is important to keep in mind that propagating isotope scales between laboratories also requires inclusion and propagation of the uncertainty of the respective isotope scale anchor.

In summary, the absence of unique CRMs for $\delta^{2} \mathrm{H}-\mathrm{CH}_{4}$ and $\delta^{13} \mathrm{C}-\mathrm{CH}_{4}$ led to a diversity of calibration trajectories. Significant calibration offsets between laboratories on the order of $0.05-0.09 \%$ ofor $\delta^{13} \mathrm{C}-\mathrm{CH}_{4}$ were identified through co-located measurements by Levin et al. (2012) and Schaefer et al. (2016), while Bock et al. (2014) reported laboratory offsets of up to $15 \%$ of $\delta^{2} \mathrm{H}-\mathrm{CH}_{4}$. Even though interlaboratory differences can be established experimentally, e.g. by co-located measurements or regular round robins, such comparisons are not intended to re-define local scale anchors to the VPDB and VSMOW isotope scales (WMO, 2014) and can therefore not replace a unifying scale anchor.

Until recently, a comparable problem existed for observations of isotope ratios in atmospheric $\mathrm{CO}_{2}$. Ghosh et al. (2005) established a method to produce synthetic $\mathrm{CO}_{2}-$ in-air standards, comprising of isotopically calibrated $\mathrm{CO}_{2}$ and $\mathrm{CO}_{2}$-free air. The concept of these $\mathrm{CO}_{2}$-in-air standards is to provide a matrix reference material (m-RM), which is defined as RM that is mixed with matrix material to match the composition of the samples (IAEA, 2003). Since 2005, the ISOLAB of the Max Planck Institute for Biogeochemistry (MPI-BGC) in Jena, Germany, distributes a suite of mRMs, known as JRAS (Jena Reference Air Set), which is accepted as an isotope scale anchor by the community (WMO, 2012). Calibrating against the JRAS reduces laboratory offsets and has proven a successful method to reach and maintain the compatibility goal for isotope ratios in atmospheric $\mathrm{CO}_{2}$ (Wendeberg et al., 2013).

This paper describes an analogue method to produce synthetic $\mathrm{CH}_{4}$-in-air standards for $\delta^{2} \mathrm{H}-\mathrm{CH}_{4}$ and $\delta^{13} \mathrm{C}-\mathrm{CH}_{4}$, which we refer to as JRAS-M16 (short for JRAS-Methane 2016). We present new methods to calibrate a suite of isotopically different $\mathrm{CH}_{4}$ gases, which span over a large isotopic range. We calibrate two $\mathrm{CH}_{4}$ gases for $\delta^{2} \mathrm{H}$ and $\delta^{13} \mathrm{C}$ and compare our results to independent calibrations made at a partnering laboratory to demonstrate the comparability of our new methods, thereby fulfilling the requirement to use two independent analytical methods during the development of quality control materials (QCMs) when CRMs are not available (IAEA, 2003). We produce synthetic $\mathrm{CH}_{4}$-in-air standards by diluting aliquots of calibrated $\mathrm{CH}_{4}$ with $\mathrm{CH}_{4}$ free synthetic air and include the full traceability chain in the uncertainty budget. Calibrated $\delta^{2} \mathrm{H}-\mathrm{CH}_{4}$ and $\delta^{13} \mathrm{C}-\mathrm{CH}_{4}$ values in our synthetic $\mathrm{CH}_{4}$-in-air standards bracket tropospheric values and enable two-point calibrations to account for scale compression effects (Coplen et al., 2006a). Our synthetic $\mathrm{CH}_{4}$-in-air standards can be tested by other laboratories in the community; alternatively, compressed air cylinders from other laboratories can be calibrated at MPI-BGC. Our long-term strategy is to establish JRAS-M16 as m-RM for $\delta^{2} \mathrm{H}-\mathrm{CH}_{4}$ and $\delta^{13} \mathrm{C}-\mathrm{CH}_{4}$ in the future. We hope that our efforts help the community to reach the scale anchor compat- 


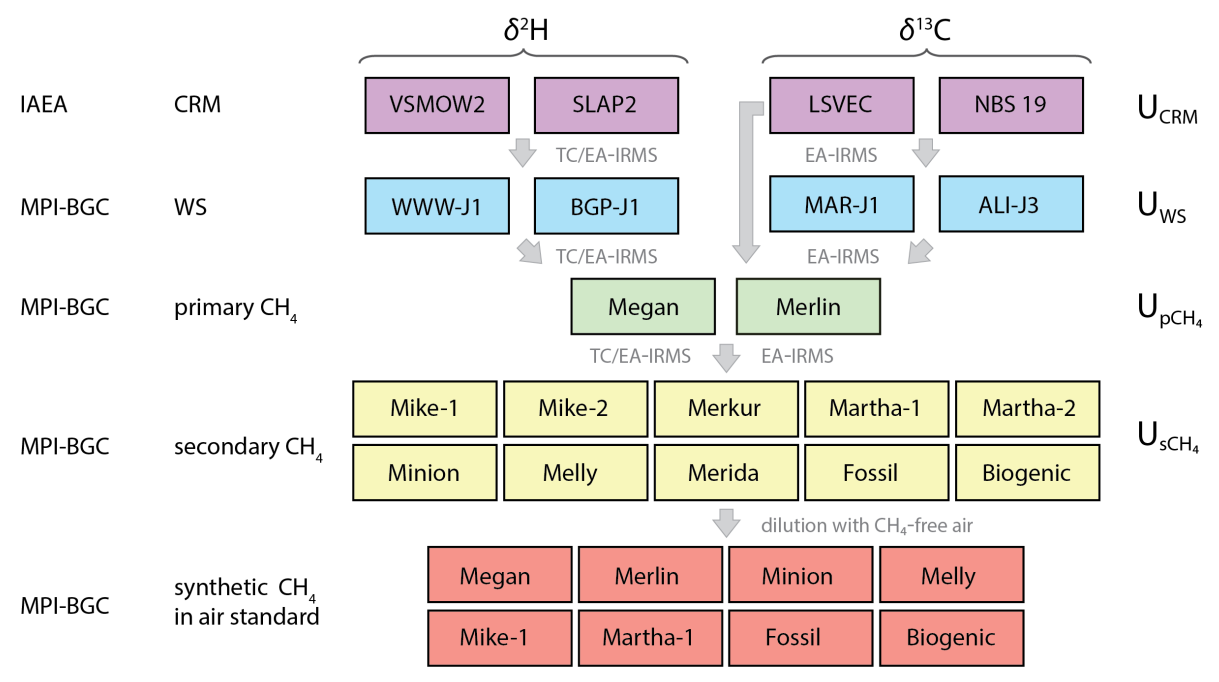

Figure 1. Calibration hierarchy to produce synthetic $\mathrm{CH}_{4}$-in-air standards including links of the traceability chain. The long, central arrow shows that the primary $\mathrm{CH}_{4}$ gases were directly calibrated against CRMs for $\delta^{13} \mathrm{C}$ but not for $\delta^{2} \mathrm{H}$. The uncertainty $(U)$ associated with each calibration hierarchy level is indicated by indices that are described in Sect. 2.4.

ibility goals of 1 and $0.02 \%$ for $\delta^{2} \mathrm{H}-\mathrm{CH}_{4}$ and $\delta^{13} \mathrm{C}-\mathrm{CH}_{4}$ respectively (WMO, 2014).

\section{Materials and methods}

Throughout this paper, we use the terminology of "calibration" and "measurement" with different intentions. We use calibration when samples are repeatedly compared against measurement standards of the highest possible hierarchy level (possible hierarchy levels include CRMs and WSs) in order to determine the isotopic composition of the analyte under consideration of the full traceability chain. In contrast, we use the measurement term when the analysis is not necessarily based on measurement standards of highest possible hierarchy level, when the achievable uncertainty of the analysis is not of primary importance or when the uncertainty does not necessarily include the full traceability chain. For example, we use the measurement term for the experiments to establish the dependence of isotope ratios in the analyte on reactor temperatures of the analytical system.

The aim of our method is to calibrate and prepare synthetic $\mathrm{CH}_{4}$-in-air standards, as outlined in the flow diagram of Fig. 1. Therefore, we calibrate two pure $\mathrm{CH}_{4}$ gases for their $\delta^{2} \mathrm{H}-\mathrm{CH}_{4}$ and $\delta^{13} \mathrm{C}-\mathrm{CH}_{4}$ isotope ratios against CRMs and WSs, where the latter are of comparable chemical composition to the former. We refer to these two $\mathrm{CH}_{4}$ gases as primary $\mathrm{CH}_{4}$ gases. The primary $\mathrm{CH}_{4}$ gases are then used to calibrate a suite of pure $\mathrm{CH}_{4}$ gases, which we refer to as secondary $\mathrm{CH}_{4}$ gases. The analytical methods we developed for $\delta^{2} \mathrm{H}-\mathrm{CH}_{4}$ and $\delta^{13} \mathrm{C}-\mathrm{CH}_{4}$ calibrations are based on well-established IRMS methods, thereby complying with the requirements to use established analytical systems for the production of QCMs when CRMs are not available (IAEA,
2003). Once calibrated, aliquots of both primary and secondary $\mathrm{CH}_{4}$ gases are diluted with $\mathrm{CH}_{4}$-free air to atmospheric $\mathrm{CH}_{4}$ mole fractions. We analyse the resulting synthetic $\mathrm{CH}_{4}$-in-air standards on a new analytical system that is designed to analyse atmospheric samples, thereby complying with the principle of identical treatment (PIT; Werner and Brand, 2001) during the analysis of the synthetic $\mathrm{CH}_{4}$-in-air standards. This enables us to determine the calibration difference between JRAS-M16 and the hitherto adopted method to reference $\delta^{2} \mathrm{H}-\mathrm{CH}_{4}$ and $\delta^{13} \mathrm{C}-\mathrm{CH}_{4}$ in atmospheric samples to the VSMOW and VPDB scales respectively. This difference represents the laboratory specific correction that has to be applied to anchor all measurements from MPI-BGC to the new JRAS-M16 scale.

\subsection{Gases, reference materials and hierarchy levels of calibrations}

Our study is based on a suite of $\mathrm{CH}_{4}$ gases that differ in their methanogenic origin and therefore in their isotopic composition. We identify our $\mathrm{CH}_{4}$ gases by names as shown in Table 1. "Biogenic" and "Fossil" have been calibrated at the Centre for Ice and Climate (CIC), which is a department of the Niels Bohr Institute at the University in Copenhagen, Denmark (Sperlich et al., 2012). These gases allow testing and evaluating the performance of the analytical systems at MPI-BGC with independent methods, which is a required control mechanism for the development of QCMs when CRMs are not available (IAEA, 2003). Six other $\mathrm{CH}_{4}$ gases were purchased from suppliers of commercial gases or laboratory equipment (Air-Liquide, Westfalen AG, Linde, Messer, Campro Scientific) and were used as purchased or as mixtures thereof. The purity level of all our $\mathrm{CH}_{4}$ gases is 


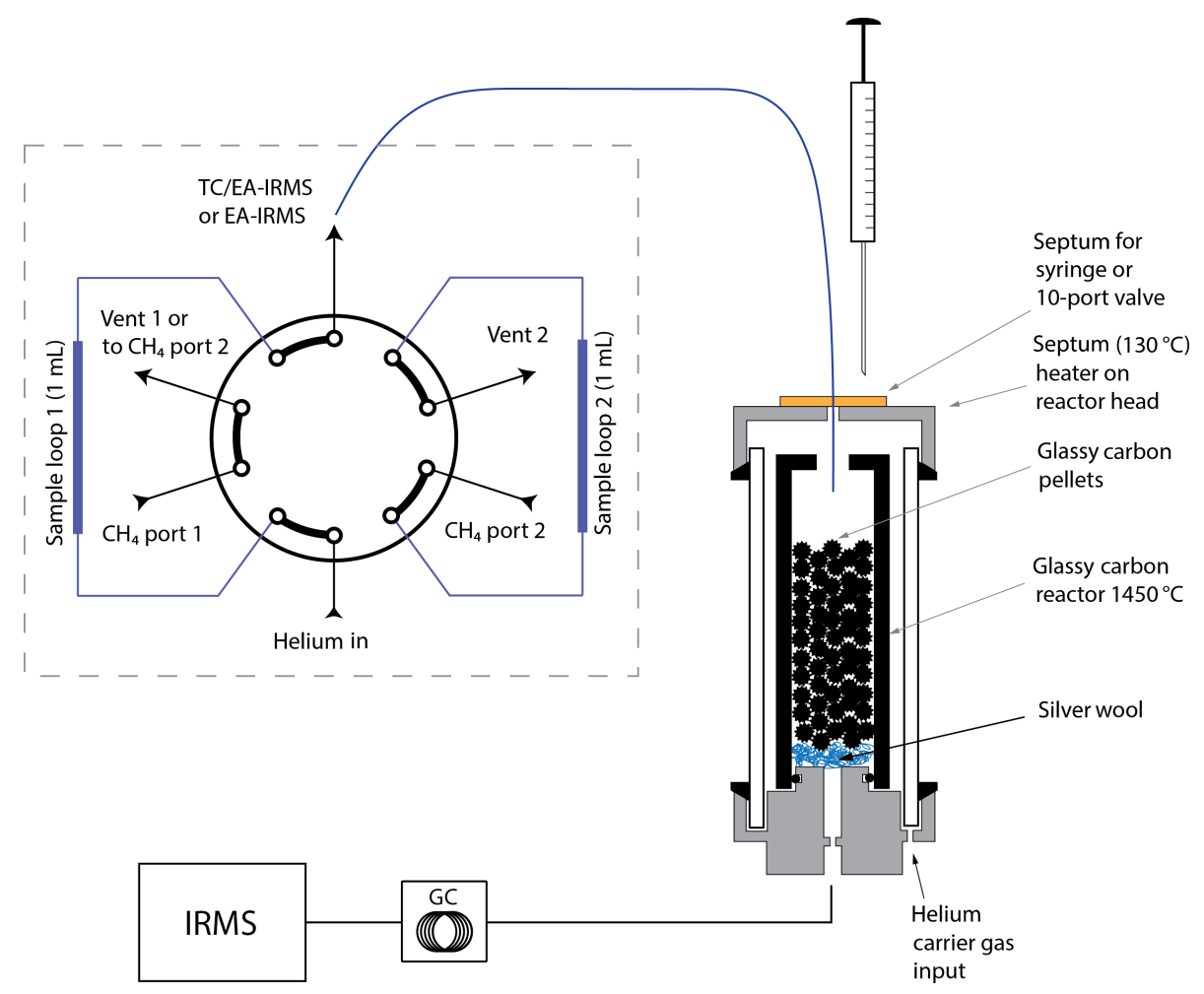

Figure 2. Configuration of manual the two-position 10-port valve with two $1 \mathrm{~mL}$ sample loops shown in grey dashed box and TC/EA-IRMS system for $\delta^{2} \mathrm{H}-\mathrm{CH}_{4}$ calibration. The TC/EA-IRMS reactor (displayed as in Gehre et al., 2004) is fed either by the sample line from the 10 -port valve or by the syringe via autosampler (not shown). The size of components is chosen to increase clarity.

$\geq 99.995 \%$. Our goals were to produce (i) a suite of $\mathrm{CH}_{4}$ gases that encompasses the isotopic composition of tropospheric $\mathrm{CH}_{4}$, and (ii) $\mathrm{CH}_{4}$ gases that closely match the isotopic composition of tropospheric $\mathrm{CH}_{4}$. For $\delta^{2} \mathrm{H}-\mathrm{CH}_{4}$ this was achieved by spiking fossil $\mathrm{CH}_{4}$ gases with pure $\mathrm{CH}_{3} \mathrm{D}$ to yield "Martha-1", "Martha-2" and "Mike-1". Mike-1 was then mixed with a fossil $\mathrm{CH}_{4}$ gas to produce "Mike-2" while Martha-1 was spiked with pure $\mathrm{CH}_{3} \mathrm{D}$ to produce "Martha2". Martha-1 and Mike-1 were thereby transitional $\mathrm{CH}_{4}$ mixtures.

We calibrated "Megan" and "Merlin" for $\delta^{2} \mathrm{H}-\mathrm{CH}_{4}$ and $\delta^{13} \mathrm{C}-\mathrm{CH}_{4}$ as primary $\mathrm{CH}_{4}$ gases (Fig. 1) against CRMs and WSs to the VSMOW and VPDB isotope scales respectively. Applied WSs are identical or similar in chemical composition to available CRMs in most cases (Table 2). All secondary $\mathrm{CH}_{4}$ gases were calibrated against the primary $\mathrm{CH}_{4}$ gases and are therefore of lower hierarchy level in the calibration scheme (Fig. 1). Megan was used as primary $\mathrm{CH}_{4}$ gas for all initial experiments and our first calibrations of secondary $\mathrm{CH}_{4}$ gases, until it was accidentally vented to ambient in March 2015. In order to compensate for the loss, we calibrated Merlin against CRMs and WSs as primary $\mathrm{CH}_{4}$ in replacement of Megan.

\subsection{Referencing pure $\mathrm{CH}_{4}$ for $\delta^{2} \mathrm{H}$ against VSMOW/SLAP and against other pure $\mathrm{CH}_{4}$ gases}

We use a high-temperature conversion elemental analyser (TC/EA) coupled to an isotope ratio mass spectrometer (IRMS; Delta Plus XL, Thermo Finnigan, Bremen, Germany) via an open split (ConFlo III, Thermo Finnigan, Bremen, Germany). The system at MPI-BGC is operated for $\delta^{2} \mathrm{H}-\mathrm{H}_{2} \mathrm{O}$ and $\delta^{18} \mathrm{O}-\mathrm{H}_{2} \mathrm{O}$ analysis with high precision and negligible systematic errors since more than a decade (Gehre et al., 2004; Brand et al., 2009a) and is depicted in Fig. 2. Because TC/EA-IRMS systems are also used for $\delta^{2} \mathrm{H}$ analysis in hydrocarbons (e.g. Hilkert et al., 1999; Schimmelmann et al., 2016), this method is particularly suitable to calibrate $\delta^{2} \mathrm{H}-\mathrm{CH}_{4}$ against reference $\mathrm{H}_{2} \mathrm{O}$ (CRM and WS, Table 2). Therefore, we inject $\mathrm{CH}_{4}$ and $\mathrm{H}_{2} \mathrm{O}$ samples through an externally heated septum (kept at $130^{\circ} \mathrm{C}$ ) into the glassy carbon reactor of the TC/EA-IRMS (kept at $1450^{\circ} \mathrm{C}$ ), where both species are converted to $\mathrm{H}_{2}$ (+ carbon or $\mathrm{CO}$ ). A helium carrier gas transports the sample gases from the hightemperature reactor through a gas chromatographic (GC) column $\left(1 / 4 \mathrm{in}\right.$. OD, $60 \mathrm{~cm}$ length, 5 - $\AA$ zeolite, $\left.75^{\circ} \mathrm{C}\right)$ and into the open split. $\mathrm{CH}_{4}$ injections are made with a two position 10-port valve (VICI, USA), which is configured as depicted in Fig. 2. A helium stream of $15 \mathrm{~mL} \mathrm{~min}^{-1}$ carries $\mathrm{CH}_{4}$ sam- 
Table 1. Gases used for this study. Note that Mike- 1 and Martha-1 were transitional $\mathrm{CH}_{4}$ mixtures and do not exist anymore.

\begin{tabular}{|c|c|c|c|c|c|}
\hline Gas name & $\begin{array}{r}\text { Cylinder } \\
\text { volume }(\mathrm{L})\end{array}$ & Pressure (bar) & Function in study & $\mathrm{CH}_{4}$ source & Gas supplier \\
\hline Megan & 10 & - & first primary $\mathrm{CH}_{4}$ (lost) & fossil $\mathrm{CH}_{4}$ & Air Liquide, Germany \\
\hline Merlin & 10 & 190 & second primary $\mathrm{CH}_{4}$ (replacement of Megan) & fossil $\mathrm{CH}_{4}$ & Air Liquide, Germany \\
\hline Mike-1 & - & - & secondary $\mathrm{CH}_{4}$ & MPI mixture & MPI-BGC \\
\hline Mike-2 & 5 & 45 & secondary $\mathrm{CH}_{4}$ & MPI mixture & MPI-BGC \\
\hline Merkur & 2 & 100 & secondary $\mathrm{CH}_{4}$ & fossil $\mathrm{CH}_{4}$ & Messer Griesheim, Germany \\
\hline Merida & 10 & 175 & secondary $\mathrm{CH}_{4}$ & unknown & Westfalen AG, Germany \\
\hline Martha-1 & - & - & secondary $\mathrm{CH}_{4}$ & MPI mixture & MPI-BGC \\
\hline Martha-2 & 10 & 165 & secondary $\mathrm{CH}_{4}$ & MPI mixture & MPI-BGC \\
\hline Minion & 3 & 150 & secondary $\mathrm{CH}_{4}$ & unknown & Messer Griesheim, Germany \\
\hline Melly & 50 & 193 & secondary $\mathrm{CH}_{4}$ & unknown & Westfalen AG, Germany \\
\hline$\delta^{2} \mathrm{H}$-spike gas & 0.4 & 2.5 & $\mathrm{CH}_{3} \mathrm{D}$ spiking gas & & Campro Scientific, Germany \\
\hline Fossil & 30 & 2 & secondary $\mathrm{CH}_{4}$ and comparison & fossil $\mathrm{CH}_{4}$ & Air Liquide, Denmark \\
\hline Biogenic & 30 & 2 & secondary $\mathrm{CH}_{4}$ and comparison & biogas plant & Biogas Plant, Germany \\
\hline synthetic air & 50 & 200 & Synthetic air matrix & & Linde, Germany \\
\hline Krypton & 2 & 200 & synthetic air matrix & & Westfalen AG, Germany \\
\hline Carina-1 & 50 & 200 & working standard and scale comparison & Jena air & MPI-BGC \\
\hline Carina-2 & 50 & 200 & working standard and scale comparison & Jena air & MPI-BGC \\
\hline
\end{tabular}

Table 2. Measurement standards used in this study. "CRM" and "WS" identify certified reference material and in-house working standards respectively. The uncertainties of the $\delta^{2} \mathrm{H}$ and $\delta^{13} \mathrm{C}$ data from MPI-BGC correspond to the $95 \%$ confidence limit of the error of the mean. We include the uncertainty estimate that the IAEA recently suggested for LSVEC. Publications and additional comments related to the standards are listed in the last column.

\begin{tabular}{|c|c|c|c|c|c|c|}
\hline Name & Material & $\mathrm{CRM} / \mathrm{WS}$ & $\delta^{2} \mathrm{H}[\% o]$ & $\delta^{13} \mathrm{C}[\% o]$ & Source & Reference/comment \\
\hline VSMOW2 & $\mathrm{H}_{2} \mathrm{O}$ & CRM & $0 \pm 0.3$ & - & IAEA & $\begin{array}{l}\text { Gröning et al. (2007), Brand et } \\
\text { al. (2014) }\end{array}$ \\
\hline SLAP2 & $\mathrm{H}_{2} \mathrm{O}$ & CRM & $-427.5 \pm 0.3$ & - & IAEA & $\begin{array}{l}\text { Gröning et al. (2007), Brand et } \\
\text { al. (2014) }\end{array}$ \\
\hline GISP & $\mathrm{H}_{2} \mathrm{O}$ & CRM & $-189.7 \pm 0.9$ & & IAEA & Brand et al. (2014) \\
\hline NBS 19 & $\mathrm{CaCO}_{3}$ & CRM & & $+1.95 \pm 0.00$ & IAEA & Brand et al. (2014), exhausted \\
\hline LSVEC & $\mathrm{Li}_{2} \mathrm{CO}_{3}$ & CRM & - & $-46.6 \pm 0.15$ & IAEA & $\begin{array}{l}\text { Coplen et al. (2006b), Qi et al. (2016), } \\
\text { Schimmelmann et al. (2016) }\end{array}$ \\
\hline $\mathrm{CO}-9$ & $\mathrm{BaCO}_{3}$ & CRM & - & $-47.32 \pm 0.06$ & IAEA & Coplen et al. (2006b) \\
\hline RM 8563 & $\mathrm{CO}_{2}$ & CRM & & $-41.59 \pm 0.06$ & & Coplen et al. (2006b), exhausted \\
\hline WWW-J1 & $\mathrm{H}_{2} \mathrm{O}$ & WS & $-67.0 \pm 0.4$ & & MPI-BGC & - \\
\hline BGP-J1 & $\mathrm{H}_{2} \mathrm{O}$ & WS & $-187.1 \pm 0.6$ & & MPI-BGC & - \\
\hline MAR-J1 & $\mathrm{CaCO}_{3}$ & WS & & $+1.96 \pm 0.01$ & MPI-BGC & Brand et al. (2009b) \\
\hline ALI-J3 & Acetanilide & WS & & $-30.06 \pm 0.05$ & MPI-BGC & - \\
\hline Cecily & $\mathrm{CO}_{2}$ & WS & & $-3.84 \pm 0.015$ & MPI-BGC & - \\
\hline Carina-1 & Jena air & WS & $-82.7 \pm 4.0$ & $-47.61 \pm 0.09$ & MPI-BGC & $\begin{array}{l}\text { calibration (T. Röckmann, personal } \\
\text { communication, 2013) }\end{array}$ \\
\hline Carina-2 & Jena air & WS & $-85.5 \pm 4.0$ & $-47.62 \pm 0.12$ & MPI-BGC & $\begin{array}{l}\text { calibration (T. Röckmann, personal } \\
\text { communication, 2013) }\end{array}$ \\
\hline
\end{tabular}

ples from the $1 \mathrm{~mL}$ sample loops into the TC/EA reactor. Typical $\mathrm{CH}_{4}$ flow rates range between 2 and $3 \mathrm{~mL} \mathrm{~min}^{-1}$. For the calibrations of primary $\mathrm{CH}_{4}$ gases, the two sample loops are fed by the same $\mathrm{CH}_{4}$ gas (connecting vent 1 and $\mathrm{CH}_{4}$ port 2). The sample loops are fed by two different gases for the calibration of secondary against primary $\mathrm{CH}_{4}$ gases (Table 1). While $\mathrm{CH}_{4}$ gases are injected manually, $\mathrm{H}_{2} \mathrm{O}$ is introduced via autosampler.
It is recommended to measure samples against standards with identical material-specific properties (PIT; Werner and Brand, 2001). Under such conditions, measurement artefacts are likely to cancel when, for example, $\mathrm{H}_{2} \mathrm{O}$ samples are calibrated against $\mathrm{H}_{2} \mathrm{O}$ standards. However, great care has to be taken when chemically identical or similar CRMs are not available so that sample and standard comprise materials with different chemical properties, which is the case when 
calibrating $\mathrm{CH}_{4}$ against $\mathrm{H}_{2} \mathrm{O}$. Calibration errors may arise when only one or both materials are fractionated during analysis, where the latter is likely to occur with different fractionation factors.

We performed a range of experiments to test for systematic errors during $\mathrm{H}_{2} \mathrm{O}$ and $\mathrm{CH}_{4}$ analysis. (i) System memory occurs during the isotopic analysis of $\mathrm{H}_{2} \mathrm{O}$ due to adhesion of $\mathrm{H}_{2} \mathrm{O}$ onto internal surfaces. System memory is sufficiently minimised by repeated $\mathrm{H}_{2} \mathrm{O}$ injections and rejection of the first sample in every sequence. Remaining memory effects are corrected for in the evaluation routine as shown by Gehre et al. (2004). System memory is not created by $\mathrm{CH}_{4}$ injections but some $\delta^{2} \mathrm{H}-\mathrm{CH}_{4}$ analyses may be affected by desorption of $\mathrm{H}_{2} \mathrm{O}$, stemming from previous injections. (ii) We observe a systematic effect of the septum temperature on the resulting $\delta^{2} \mathrm{H}-\mathrm{H}_{2} \mathrm{O}$ and operate the system with a septum temperature of $130^{\circ} \mathrm{C}$, where $\delta^{2} \mathrm{H}-\mathrm{H}_{2} \mathrm{O}$ was found stable. $\delta^{2} \mathrm{H}-\mathrm{CH}_{4}$ analysis is not affected by septum temperature. (iii) We experimentally optimised the TC/EA reactor temperature and found highest $\mathrm{H}_{2}$ yields, quantitative conversion and hence smallest isotopic fractionation at $1450{ }^{\circ} \mathrm{C}$ during both $\delta^{2} \mathrm{H}-\mathrm{H}_{2} \mathrm{O}$ and $\delta^{2} \mathrm{H}-\mathrm{CH}_{4}$ analysis. Appendix A describes these experiments in greater detail.

The introduction of $\mathrm{H}_{2}$ samples into the ion source of an IRMS leads to the formation of $\mathrm{H}_{3}^{+}$ions that are registered on the $\mathrm{HD}^{+}$detector, which is accounted for by the so called " $\mathrm{H}_{3}$-factor correction" (Friedman, 1953; Sessions et al., 2001). The $\mathrm{H}_{3}$-factor correction is experimentally determined and assumed to be constant until re-determined. Determining the $\mathrm{H}_{3}$-factor correction is part of the daily preparation routine at MPI-BGC and shows only minor variation with time. Theoretically, the $\mathrm{H}_{3}^{+}$formation could be dynamic during the experimental period with unknown variability. We matched the $\mathrm{H}_{2}$ peak heights resulting from both $\mathrm{CH}_{4}$ and $\mathrm{H}_{2} \mathrm{O}$ injections around $5.5 \pm 0.5 \mathrm{~V}$ in order to minimise the impact of imperfect $\mathrm{H}_{3}$-factor correction. Peak widths ranged around 45 and $60 \mathrm{~s}$ for $\mathrm{H}_{2} \mathrm{O}$ - and $\mathrm{CH}_{4}$-derived $\mathrm{H}_{2}$ peaks respectively. A typical chromatogram of the $\delta^{2} \mathrm{H}-\mathrm{CH}_{4}$ calibration including details on peak shape and background is shown in Fig. 3. The similarity between $\mathrm{CH}_{4}$-derived and the $\mathrm{H}_{2} \mathrm{O}$-derived $\mathrm{H}_{2}$ peaks allows the use of the standard integration software (ISODAT, Thermo Finnigan, Bremen, Germany).

Megan and Merlin (Table 1) were calibrated in three independent sequences during 3 days against the in-house working standards "WWW-J1" and "BGP-J1" with a wide $\delta^{2} \mathrm{H}$ range from -67.0 to $-187.1 \%$ (Table 2). WWW-J1 and BGP-J1 are independently calibrated against international reference waters VSMOW2 and SLAP2 (Table 2). Other $\mathrm{CH}_{4}$ gases were initially also measured against working standards (WWW-J1 and BGP-J1) but were finally calibrated against Megan or Merlin, which were co-analysed in the same measurement sequence in a one-point calibration.
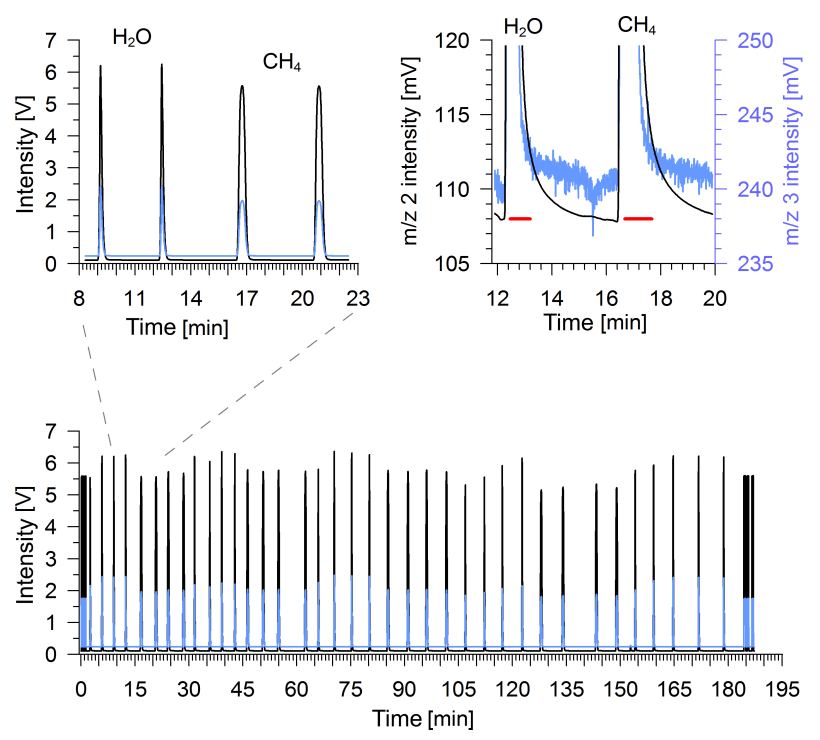

Figure 3. Chromatograms of $\delta^{2} \mathrm{H}-\mathrm{CH}_{4}$ calibration sequences using TC/EA-IRMS with traces of $m / z 2$ and $m / z 3$ shown in black and blue respectively. The bottom panel shows an example of an entire calibration sequence which begins with three square-shaped peaks of pure $\mathrm{H}_{2}$, followed by alternations of three to four $\mathrm{H}_{2} \mathrm{O}$ - and three to four $\mathrm{CH}_{4}$-derived $\mathrm{H}_{2}$ peaks before the sequence ends with another three square-shaped peaks of pure $\mathrm{H}_{2}$. The top left panel enlarges $\mathrm{H}_{2}$ peaks from $\mathrm{H}_{2} \mathrm{O}$ (peak no. 6-7) and $\mathrm{CH}_{4}$ (peak no. 8-9) injections respectively. A zoom into baseline details of $\mathrm{H}_{2} \mathrm{O}$ derived peak no. 7 and $\mathrm{CH}_{4}$-derived peak no. 8 is shown in the top right panel. Red lines indicate the sections used for peak integration (weak widths are 43 and $59 \mathrm{~s}$ for $\mathrm{H}_{2} \mathrm{O}$ - and $\mathrm{CH}_{4}$-derived $\mathrm{H}_{2}$ peaks respectively) by the IRMS software.

\subsection{Referencing pure $\mathrm{CH}_{4}$ for $\delta^{13} \mathrm{C}$ against LSVEC/MAR-J1 and against other pure $\mathrm{CH}_{4}$ gases}

We calibrated $\delta^{13} \mathrm{C}-\mathrm{CH}_{4}$ in pure $\mathrm{CH}_{4}$ gases after conversion to $\mathrm{CO}_{2}$ using an elemental analyser (EA 1100, CE, Rodano, Italy) coupled to an IRMS (Delta Plus, Thermo Finnigan, Bremen, Germany) via open split (ConFlo III, Thermo Finnigan, Bremen, Germany). This system is routinely used for the analysis of ${ }^{13} \mathrm{C}$ and ${ }^{15} \mathrm{~N}$ in samples with solid or liquid matrices (Werner et al., 1999; Brooks et al., 2003). We fitted a $1 / 16$ in. tube of $70 / 30 \% \mathrm{Cu} / \mathrm{Ni}$ alloy to the EA and used the previously described 10-port valve to inject the $\mathrm{CH}_{4}$ samples into the EA with a $10 \mathrm{~mL} \mathrm{~min}^{-1}$ helium flow (Fig. 4).

The plumbing of the system is designed so that gaseous $\mathrm{CH}_{4}$ and solid CRMs/WSs are applied to the same location inside the combustion reactor of the EA. All samples are combusted at a reactor temperature of $1020^{\circ} \mathrm{C}$ (Werner et al., 1999) and experience identical analytical treatment thereafter. Following the combustion, each sample passes through a reduction reactor filled with elemental copper, which is kept at $650^{\circ} \mathrm{C}$ to remove excess $\mathrm{O}_{2}$ and to reduce $\mathrm{NO}_{x}$ if present. The sample is dried by passing through a Nafion ${ }^{\mathrm{TM}}$ membrane (Perma Pure LLC, Toms River, NJ, USA; not shown in 


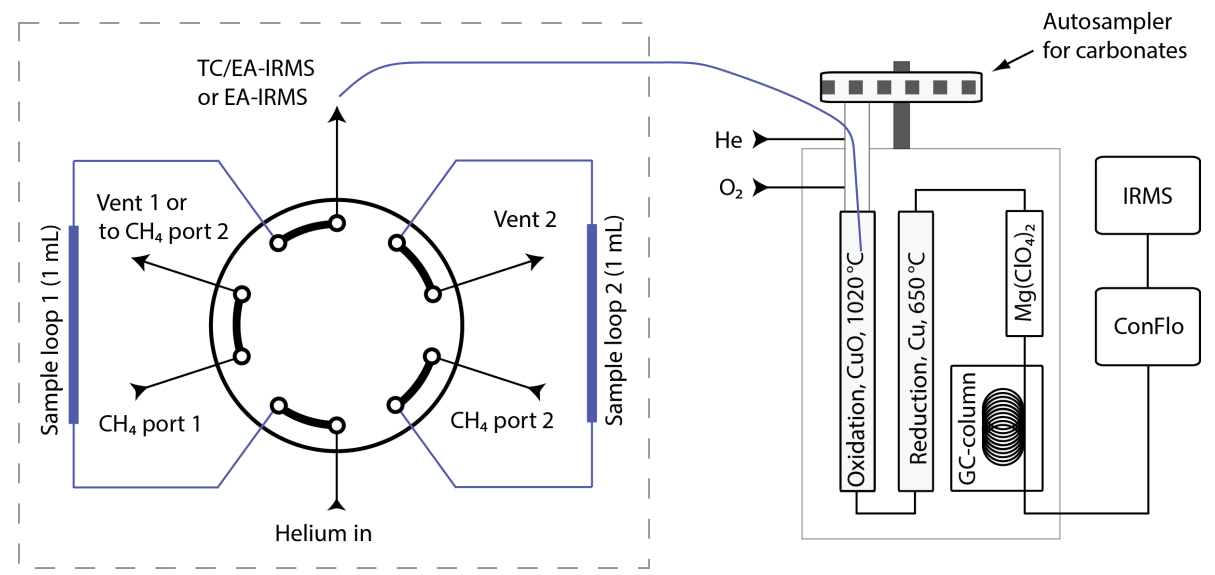

Figure 4. The 10-port valve for manual $\mathrm{CH}_{4}$ injections is coupled to the EA-IRMS system through custom-made gas inlet into combustion (oxidation) unit for $\delta^{13} \mathrm{C}-\mathrm{CH}_{4}$ calibration. The proportions of illustrated components are chosen to increase clarity.

Fig. 4) and a $\mathrm{Mg}\left(\mathrm{ClO}_{4}\right)_{2}$ trap before it enters the $\mathrm{GC}$ column ( $3 \mathrm{~m}, 1 / 4$ in.; Porapak PQS, CE instruments) held at $80^{\circ} \mathrm{C}$. Thereafter, the sample enters the IRMS through the open split.

Measurement sequences to calibrate primary $\mathrm{CH}_{4}$ gases to the VPDB isotope scale are created by alternating blocks of manual $\mathrm{CH}_{4}$ injections and CRM/WS (Table 2) applications via autosampler. We applied one WS and one CRM (LSVEC) to calibrate the primary $\mathrm{CH}_{4}$ gases in a two-point calibration. While MAR-J1 was used as WS in most experiments, ALI-J1 was used once, during a calibration of Merlin. Megan and Merlin were each calibrated on 3 different days to determine the external reproducibility of the $\delta^{13} \mathrm{C}$ results. Chromatograms resulting from $\mathrm{CH}_{4}$ and from carbonate analyses using EA-IRMS are displayed in Fig. 5 and show very similar peak shapes for $\mathrm{CH}_{4}$ and carbonates. Typical $\mathrm{m} / z$ $44 \mathrm{am}-$ plitudes and peak widths were $\sim 7.4 \pm 0.2 \mathrm{~V}$ and $101 \pm 1 \mathrm{~s}$ for both materials respectively. We connected a primary $\mathrm{CH}_{4}$ and a secondary $\mathrm{CH}_{4}$ gas to the 10-port valve to calibrate the secondary $\mathrm{CH}_{4}$ gases (Table 1 ) for $\delta^{13} \mathrm{C}$ in a one-point calibration. All measurement results were corrected for scale compression based on the method suggested in Verkouteren and Klinedinst (2004), using an empirical, mass spectrometer specific correction factor of 1.0056 .

\subsection{Measurement uncertainty and error propagation}

The fully propagated uncertainty for the primary $\mathrm{CH}_{4}$ gases $\left(U_{\mathrm{pCH} 4-\text { tot }}\right)$ is calculated as

$U_{\mathrm{pCH}_{4}-\mathrm{tot}}=\sqrt{u_{\mathrm{CRM}}^{2}+u_{\mathrm{WS}}^{2}+u_{\mathrm{pCH}_{4}}^{2}}$

where $u_{\mathrm{CRM}}, u_{\mathrm{WS}}$ and $u_{\mathrm{pCH} 4}$ indicate the uncertainty of the $\mathrm{CRM}$, the applied working standards and the respective primary $\mathrm{CH}_{4}$ gas respectively. Both $u_{\mathrm{WS}}$ and $u_{\mathrm{pCH} 4}$ are calculated as the standard error of the mean of all measurements,
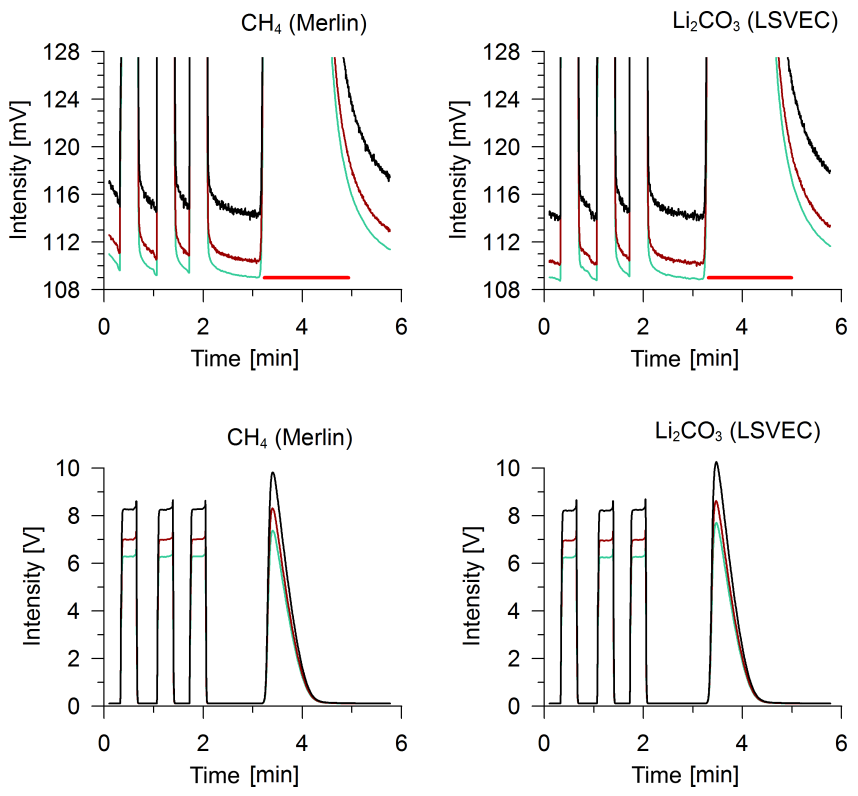

Figure 5. Chromatograms of $\delta^{13} \mathrm{C}-\mathrm{CH}_{4}$ calibrations using EA-IRMS with traces for $m / z 44,45$ and 46 in green, brown and black respectively. Bottom panels show complete chromatograms of $\mathrm{CH}_{4}$ and $\mathrm{Li}_{2} \mathrm{CO}_{3}$ analyses while the two top panels zoom into the baseline of the traces. The first three square-shaped peaks stem from injections of a pure $\mathrm{CO}_{2}$ WS while the more Gaussian-shaped peaks result from $\mathrm{CH}_{4}$ - and $\mathrm{Li}_{2} \mathrm{CO}_{3}$-derived $\mathrm{CO}_{2}$ analysis. The two red lines indicate the sections that the IRMS software uses for peak integration $\left(\mathrm{CO}_{2}\right.$ peak widths are 101 and $100 \mathrm{~s}$ for $\mathrm{CH}_{4}$ and $\mathrm{Li}_{2} \mathrm{CO}_{3}$ analysis respectively).

multiplied by $t$, Student's factor for a $95 \%$ confidence limit to account for the limited number of measurements.

The uncertainty for the secondary $\mathrm{CH}_{4}$ gases $\left(U_{\mathrm{sCH} 4-\text { tot }}\right)$ is then calculated as

$U_{\mathrm{sCH}_{4}-\text { tot }}=\sqrt{U_{\mathrm{pCH}_{4}-\mathrm{tot}}^{2}+u_{\mathrm{sCH}_{4}}^{2}}$, 
where $u_{\mathrm{sCH} 4}$ is the standard error of the mean of all measurements of the respective secondary $\mathrm{CH}_{4}$ gas, multiplied by $t$, Student's factor for a $95 \%$ confidence limit. Therefore, $U_{\mathrm{pCH} 4-\text { tot }}$ and $U_{\mathrm{sCH} 4-\text { tot }}$ indicate the fully propagated uncertainty onto the VPDB or VSMOW isotope scales, representing the traceability chain.

Note that the isotopic composition of LSVEC (Table 2) was recently found to show significant variability, most likely due to adhesion of $\mathrm{H}_{2} \mathrm{O}$ and reaction with air- $\mathrm{CO}_{2}$ (e.g. Qi et al., 2016; Schimmelmann et al., 2016). Until this problem is solved, the IAEA, one of the providers of LSVEC, advised to increase the uncertainty of LSVEC, which was hitherto assigned to $0.00 \%$. We follow the recommendation by S. Assonov (Sergey Assonov, IAEA, personal communication, 2016) and Schimmelmann et al. (2016) and adopt an uncertainty of $0.15 \%$ for the $\delta^{13} \mathrm{C}$ of LSVEC. Note that the new $0.15 \%$ uncertainty of LSVEC represents the largest single contributor to the total uncertainty budget in our $\delta^{13} \mathrm{C}$ calibrations. As a consequence we present the combined uncertainty of the full traceability chain in two versions, the first being the hitherto adopted method using an uncertainty of $0.00 \%$ for LSVEC and the second being the method with uncertainty for LSVEC of $0.15 \%$.

\subsection{Producing synthetic $\mathrm{CH}_{4}$-in-air standards from pure $\mathrm{CH}_{4}$ and $\mathrm{CH}_{4}$-free air (JRAS-M16)}

The MPI-BGC operates an analytical system (named ARAMIS) to dilute pure $\mathrm{CO}_{2}$ with $\mathrm{CO}_{2}$-free air to atmospheric $\mathrm{CO}_{2}$ mole fraction without isotopic fractionation (Ghosh et al., 2005). We use ARAMIS to dilute an aliquot of primary or secondary $\mathrm{CH}_{4}$ with $\mathrm{CH}_{4}$-free air to atmospheric $\mathrm{CH}_{4}$ mole fractions $(\sim 2 \mathrm{ppm})$ in $5 \mathrm{~L}$ glass flasks with a final filling pressure of 1.8 bar absolute. The produced synthetic $\mathrm{CH}_{4}$-in-air standards represent the JRAS-M16 reference gases. The $\mathrm{CH}_{4}$-free matrix air has been target-mixed from ultra-pure constituents and contains $\mathrm{N}_{2}, \mathrm{O}_{2}, \mathrm{~N}_{2} \mathrm{O}$ and $\mathrm{Kr}$ at atmospheric levels, so that the composition of the produced $\mathrm{CH}_{4}$-in-air standards is as close to ambient air as possible. Krypton was added to this matrix air to account for the measurement artefact during GC-IRMS analysis of $\mathrm{CH}_{4}$ for $\delta^{13} \mathrm{C}$ (Schmitt et al., 2013). A blank analysis of the $\mathrm{CH}_{4}$ free air yielded a maximum $\mathrm{CH}_{4}$ blank of $0.5 \mathrm{ppb}$. Because such a $\mathrm{CH}_{4}$ blank is too small for accurate isotopic analysis on our atmospheric system (Sect. 2.6 and Brand et al., 2016), we choose a mass-balance calculation to determine the maximum blank effect in the synthetic $\mathrm{CH}_{4}$-in-air standards. Let us assume $\delta^{2} \mathrm{H}-\mathrm{CH}_{4}$ and $\delta^{13} \mathrm{C}-\mathrm{CH}_{4}$ values for the $\mathrm{CH}_{4}$ blank of -150 and $-40 \%$, respectively, that are typical for fossil $\mathrm{CH}_{4}$. Let us now mix this blank with target $\mathrm{CH}_{4}$ comprising the most depleted $\delta^{2} \mathrm{H}-\mathrm{CH}_{4}$ and $\delta^{13} \mathrm{C}-\mathrm{CH}_{4}$ values we find in our $\mathrm{CH}_{4}$ gas suite with $\delta^{2} \mathrm{H}$ of $-320 \%$ o and $\delta^{13} \mathrm{C}$ of $-70 \%$. The mixing ratio of blank:target $\mathrm{CH}_{4}$ is $1: 4000$, which reflects the ratio within a synthetic $\mathrm{CH}_{4}$-inair mixture with $2 \mathrm{ppm} \mathrm{CH}_{4}$. The maximum blank contribu- tion in this extreme scenario would be 0.04 and $0.007 \%$ for $\delta^{2} \mathrm{H}-\mathrm{CH}_{4}$ and $\delta^{13} \mathrm{C}-\mathrm{CH}_{4}$, respectively, which is negligible in both cases.

\subsection{Analytical systems to measure the isotopic composition of $\mathrm{CH}_{4}$ in air at IMAU and MPI-BGC}

IMAU: Brass and Röckmann (2010) and Sapart et al. (2011) described the system for the analysis of both $\delta^{2} \mathrm{H}$ and $\delta^{13} \mathrm{C}$ in atmospheric methane at IMAU. $\mathrm{CH}_{4}$ is separated from the other air components by cryogenic traps and gas chromatography before it is converted by either oxidation or pyrolysis for IRMS analysis on $\mathrm{CO}_{2}$ or $\mathrm{H}_{2}$ respectively. For $\delta^{13} \mathrm{C}$ an additional GC column (PoraPlotQ, $12.5 \mathrm{~m}, 0.32 \mathrm{~mm}$ ID, Agilent, the Netherlands) was added between the Nafion drying unit and the open split interface in order to remove the interferences from $\mathrm{Kr}$ (Schmitt et al., 2013).

MPI-BGC: a new system to measure $\delta^{2} \mathrm{H}-\mathrm{CH}_{4}$ and $\delta^{13} \mathrm{C}-\mathrm{CH}_{4}$ in-air samples was recently developed at the MPIBGC and is described in greater detail in Brand et al. (2016). The system at MPI-BGC is referred to as $i$ SAAC, in abbreviation for integrated System for Analysis of Atmospheric Constituents. $i$ SAAC consists of a 16-port sample carousel to take two consecutive $100 \mathrm{~mL}$ aliquots of air from a glass flask or high-pressure cylinders for parallel analysis of $\delta^{2} \mathrm{H}-\mathrm{CH}_{4}$ and $\delta^{13} \mathrm{C}-\mathrm{CH}_{4}$, respectively, by continuous-flow GC-IRMS. The two air samples are routed through two identical but independent pre-concentration lines, one for the analysis of $\delta^{2} \mathrm{H}-\mathrm{CH}_{4}$ and one for $\delta^{13} \mathrm{C}-\mathrm{CH}_{4}$. In each line, $\mathrm{CH}_{4}$ is cryogenically separated from the main air constituents in a Hayesep D-filled trap at $-130^{\circ} \mathrm{C}$ and cryo-focussed in a further Hayesep D-filled trap at $-110^{\circ} \mathrm{C}$. Each of the two analytical lines is equipped with its own cooling compressor to avoid the use of cryogenic liquids. The separated and cryofocussed $\mathrm{CH}_{4}$ sample is released into a $\mathrm{GC}$ column from where it is routed either through a pyrolysis furnace (kept at $1400^{\circ} \mathrm{C}$ ) to convert the $\mathrm{CH}_{4}$ sample to $\mathrm{H}_{2}$ for $\delta^{2} \mathrm{H}-\mathrm{CH}_{4}$ analysis or through a combustion furnace (kept at $1000^{\circ} \mathrm{C}$ ) to convert the $\mathrm{CH}_{4}$ sample to $\mathrm{CO}_{2}$ for $\delta^{13} \mathrm{C}-\mathrm{CH}_{4}$ analysis. A post-combustion GC column separates the $\mathrm{CH}_{4}$-derived $\mathrm{CO}_{2}$ from $\mathrm{Kr}$ (Schmitt et al., 2013). $\mathrm{CH}_{4}$-derived $\mathrm{H}_{2}$ and $\mathrm{CO}_{2}$ samples are introduced via open splits into dedicated IRMS instruments, one each for $\delta^{2} \mathrm{H}-\mathrm{CH}_{4}$ and $\delta^{13} \mathrm{C}-\mathrm{CH}_{4}$ analysis. $i$ SAAC has been operational since 2012 to measure air samples with a precision of 1.0 and $0.12 \%$ for $\delta^{2} \mathrm{H}-\mathrm{CH}_{4}$ and $\delta^{13} \mathrm{C}-\mathrm{CH}_{4}$ respectively. The precision is determined by the performance chart method (Werner and Brand, 2001), determined by the standard deviation $(1 \sigma)$ of all quality control standard measurements, which has been analysed once in every measurement sequence (Brand et al., 2016). The reproducibility of $\delta^{13} \mathrm{C}-\mathrm{CH}_{4}$ analyses ranges around $0.06 \%$ over the course of 1 day. All measurements on $i$ SAAC so far have been allocated to the VPDB and VSMOW scales using an inhouse WS that was calibrated against "Carina-1" (Table 1). 


\subsection{Histories to anchor $\delta^{2} \mathrm{H}-\mathrm{CH}_{4}$ and $\delta^{13} \mathrm{C}-\mathrm{CH}_{4}$ to the VSMOW and VPDB scales at IMAU and MPI-BGC}

It is the intention of all laboratories analysing $\delta^{2} \mathrm{H}-\mathrm{CH}_{4}$ and $\delta^{13} \mathrm{C}-\mathrm{CH}_{4}$ to reference their samples relative to the VSMOW and VPDB scales respectively. However, possible accuracy errors in the laboratory specific scale anchors often result in inter-laboratory offsets. In order to retrace the potential for calibration offsets between IMAU, MPI-BGC and JRAS-M16, we describe the history of the scale anchors for each laboratory.

IMAU: the calibration strategy at IMAU, including traceability chain and long-term control, is different for $\delta^{2} \mathrm{H}-\mathrm{CH}_{4}$ and $\delta^{13} \mathrm{C}-\mathrm{CH}_{4}$ (Brass and Röckmann, 2010). (i) Three synthetic gas mixtures with $\mathrm{CH}_{4}$ mole fractions of $\sim 9000 \mathrm{ppm}$ were calibrated for $\delta^{2} \mathrm{H}-\mathrm{CH}_{4}$ at the Max Planck Institute for Chemistry (MPI-C) in Mainz, Germany, using a tunable diode laser absorption spectrometer (TDLAS) technique. The TDLAS is described by Bergamaschi et al. (1994) with a measurement precision for $\delta^{2} \mathrm{H}-\mathrm{CH}_{4}$ of $5.1 \%$ and an accuracy estimate of similar magnitude. The accuracy estimate is based on a comparison with the calibrations to the VSMOW scale by Dumke et al. (1989), which marks the origin of the isotope scale anchor for $\delta^{2} \mathrm{H}-\mathrm{CH}_{4}$ at IMAU. Aliquots of the gases from Bergamaschi et al. (1994) were diluted with synthetic $\mathrm{CH}_{4}$-free air at IMAU to yield reference gases ("Cal1", "Cal2", "Cal3") with the $\delta^{2} \mathrm{H}-\mathrm{CH}_{4}$ values initially assigned at MPI-C and atmospheric $\mathrm{CH}_{4}$ levels. Improved measurement precision and inter-laboratory comparisons lead to a $\delta^{2} \mathrm{H}-\mathrm{CH}_{4}$ refinement in Cal1, $\mathrm{Cal} 2$ and $\mathrm{Cal} 3$ with recent values of $+21.1,-19.0$ and $-164.9 \%$ respectively. Cal1, Cal2 and $\mathrm{Cal} 3$ represent the primary reference gases for $\delta^{2} \mathrm{H}-\mathrm{CH}_{4}$ at IMAU and were used to calibrate the $\delta^{2} \mathrm{H}-\mathrm{CH}_{4}$ in the working standard ("SiL") to the VSMOW scale. While Cal2 and Cal3 have become exhausted, Cal1 is still used in regular checks of the calibration scale, together with a set of firn air samples (see ii) that are used for $\delta^{13} \mathrm{C}$ calibration. (ii) IMAU's working gas $\mathrm{SiL}$ has also been calibrated for $\delta^{13} \mathrm{C}-\mathrm{CH}_{4}$. This was achieved by co-analysing SiL with a suite of Antarctic firn gas samples, where the ${ }^{13} \mathrm{C}-\mathrm{CH}_{4}$ of the latter had been determined by two laboratories (MPI-C and the Laboratoire de Géologie et Géophysique de l'Environnement (LGGE), Grenoble, France), using two different techniques (Bräunlich et al., 2001). The $\delta^{13} \mathrm{C}-\mathrm{CH}_{4}$ scale anchors at LGGE and MPI-C are calibrated at MPI-C against a pure $\mathrm{CO}_{2} \mathrm{WS}$, which itself has been calibrated against NBS 19 (Bergamaschi et al., 2000), which represents the ultimate link to the VPDB scale for the scale anchor at IMAU. Using that method, the suite of firn gas samples was treated as a set of working standards to calibrate SiL to the VPDB scale by propagation from MPI-C and LGGE to IMAU. It is important to note that Brass and Röckmann (2010) highlighted that the firn gas itself is a set of samples and not to be taken for a set of calibration stan- dards. The calibration strategy was revised during 2013 to account for the Kr interference (Schmitt et al., 2013).

MPI-BGC: all measurements on $i$ SAAC use a natural air WS that was calibrated against Carina-1 at MPI-BGC. Carina- 1 and Carina-2 are natural air samples that were calibrated for $\delta^{2} \mathrm{H}-\mathrm{CH}_{4}$ and $\delta^{13} \mathrm{C}-\mathrm{CH}_{4}$ at IMAU (Table 2), using the analytical setup described by Brass and Röckmann (2010) and Sapart et al. (2011). While the calibration results of Carina-1 and Carina-2 from IMAU show excellent agreement in $\mathrm{CH}_{4}$ mole fractions (both $1910 \mathrm{ppb}$ ), in $\delta^{13} \mathrm{C}-\mathrm{CH}_{4}$ (within $0.01 \%$ ), their $\delta^{2} \mathrm{H}-\mathrm{CH}_{4}$ values differed by $2.8 \%$ (Table 2). Because both Carina cylinders were filled at the MPI-BGC with Jena air on the same day within a short period of time during stable meteorological conditions, and because their $\delta^{13} \mathrm{C}-\mathrm{CH}_{4}$ and $\mathrm{CH}_{4}$ mole fractions are in excellent agreement, a true difference in $\delta^{2} \mathrm{H}-\mathrm{CH}_{4}$ between the two Carina cylinders seems unlikely. The magnitude of the $\delta^{2} \mathrm{H}-\mathrm{CH}_{4}$ offset was smaller than the former $\delta^{2} \mathrm{H}-\mathrm{CH}_{4}$ measurement precision at IMAU of $\pm 4 \%$ (Brass and Röckmann, 2010) and was accepted as "agreement within measurement uncertainty" at the time. It is important to note that Carina-1 and Carina-2 were each calibrated on different days and in separate measurement sequences, which does not enable a direct comparison of the two gases. Therefore, a systematic calibration error in one of the two Carina gases is possible. In contrast, the superior measurement precision of $i \mathrm{SAAC}$ for $\delta^{2} \mathrm{H}-\mathrm{CH}_{4}$ of $1.0 \%$ can resolve a true $\delta^{2} \mathrm{H}-\mathrm{CH}_{4}$ difference of $2.8 \%$. However, both Carina- 1 and Carina-2 appear indistinguishable in $\delta^{2} \mathrm{H}-\mathrm{CH}_{4}$ on $i \mathrm{SAAC}$, as determined during several direct comparisons in independent measurement sequences. Therefore, the $\delta^{2} \mathrm{H}-\mathrm{CH}_{4}$ offset between Carina-1 and Carina-2 must be due to an artefact of the calibration at IMAU. Our experiments at MPI-BGC indicate that the calibration of Carina-1 is indeed flawed. The choice to use Carina- 1 as scale anchor for all $i$ SAAC measurements at MPI-BGC was made arbitrarily, before it was known that it's calibration was impacted by an artefact. In hindsight, Carina-2 would have been a better choice as VSMOW scale anchor for $\delta^{2} \mathrm{H}-\mathrm{CH}_{4}$ at MPI-BGC. This calibration offset will be furthermore addressed a future comparison with IMAU, where a new system has been developed with an improved precision in for $\delta^{2} \mathrm{H}-\mathrm{CH}_{4}$ (Röckmann et al., 2016). All $i$ SAAC measurements are anchored to the VSMOW and VPDB isotope scales based on the described scale propagation from IMAU to MPI-BGC, until JRAS-M16 is established as new m-RM for $\delta^{2} \mathrm{H}-\mathrm{CH}_{4}$ and $\delta^{13} \mathrm{C}-\mathrm{CH}_{4}$ in air.

\subsection{Comparison of the existing isotope scales at MPI-BGC with new, synthetic $\mathrm{CH}_{4}$-in-air standards}

The synthetic $\mathrm{CH}_{4}$-in-air standards produced in this study (Sect. 2.5) were analysed at MPI-BGC using iSAAC (Sect. 2.6). In that, the synthetic $\mathrm{CH}_{4}$-in-air standards 
are treated as unknown samples and their $\delta^{2} \mathrm{H}-\mathrm{CH}_{4}$ and $\delta^{13} \mathrm{C}-\mathrm{CH}_{4}$ values are determined using Carina- 1 as scale anchor (Sect. 2.7). We calculate the isotopic difference $\left(\delta_{i \mathrm{SAAC}}-\delta_{\text {pure }}\right)$ between the measurements on $i \mathrm{SAAC}$ and the calibrations of the pure $\mathrm{CH}_{4}$ gases (Sects. 2.2 and 2.3), which indicates the correction to anchor the measurements at MPI-BGC to JRAS-M16.

\subsection{Comparison between CIC and MPI-BGC}

Two $\mathrm{CH}_{4}$ gases, Biogenic and Fossil, were previously calibrated at CIC by Sperlich et al. (2012), who analysed the $\mathrm{CH}_{4}$-derived $\mathrm{CO}_{2}$ for $\delta^{13} \mathrm{C}-\mathrm{CH}_{4}$ by dual-inlet IRMS and the $\mathrm{CH}_{4}$-derived $\mathrm{H}_{2} \mathrm{O}$ for $\delta^{2} \mathrm{H}-\mathrm{CH}_{4}$ by either cavity ringdown spectroscopy (CRDS) or TC/EA-IRMS. Sperlich et al. (2012) presented the data with the measurement reproducibility, calculated as the pooled standard deviation of the measurements. Therefore, their uncertainty does not include the uncertainties of the full traceability chain. Furthermore, a statistical provision that accounts for the small number of measurements has not been made by Sperlich et al., (2012). This imposes a hurdle in the comparison with data from MPI-BGC. Therefore, we revise the uncertainty of the CIC data and calculate the full traceability chain as described in Sect. 2.4. Furthermore, all $\delta^{13} \mathrm{C}$ measurements from CIC are affected by a small offset of RM 8563 that has been reported by Coplen et al. (2006b) and are therefore shifted by $0.03 \%$ o towards more depleted $\delta^{13} \mathrm{C}$ values. Moreover, the $\delta^{13} \mathrm{C}$ data presented in Sperlich et al. (2012) have not been corrected for scale compression. We are able to correct all CIC data for this effect, because the scale compression factor of the instrument at CIC has been determined (1.0025) at the time the study of Sperlich et al. (2012) was published. Applying the scale compression correction shifts the $\delta^{13} \mathrm{C}^{-} \mathrm{CH}_{4}$ of Fossil and Biogenic by 0.01 and $0.05 \%$ o towards more depleted $\delta^{13} \mathrm{C}$ values respectively. The revised data and uncertainties from CIC and the results from MPI-BGC for Biogenic and Fossil are shown in Table 4 for $\delta^{13} \mathrm{C}-\mathrm{CH}_{4}$ and in Table 5 for $\delta^{2} \mathrm{H}-\mathrm{CH}_{4}$.

We perform two comparisons between CIC and MPIBGC. (i) The calibration results for Fossil and Biogenic from CIC as published in Sperlich et al. (2012) are compared to the calibrations at MPI-BGC using the methods to calibrate pure $\mathrm{CH}_{4}$ gases for $\delta^{2} \mathrm{H}-\mathrm{CH}_{4}$ and $\delta^{13} \mathrm{C}-\mathrm{CH}_{4}$ as described in Sects. 2.2 and 2.3. (ii) We performed new combustion experiments at $\mathrm{CIC}$ using Fossil and Biogenic and analysed the resulting $\mathrm{CO}_{2}$ for $\delta^{13} \mathrm{C}$ at both CIC and MPI-BGC. These combustion experiments were made in 2012 but after the publication of Sperlich et al. (2012). Therefore, these experiments provide new data to evaluate the method at CIC. Following the $\delta^{13} \mathrm{C}$ analyses at $\mathrm{CIC}$, the remaining $\mathrm{CO}_{2}$ gases were cryogenically transferred and flame sealed in glass ampules for $\delta^{13} \mathrm{C}$ analysis at MPI-BGC. The $\delta^{13} \mathrm{C}$ analyses at MPIBGC were made on "Cora", a MAT 252 dual-inlet IRMS (Thermo Finnigan, Bremen, Germany) that is used for $\delta^{13} \mathrm{C}$ and $\delta^{18} \mathrm{O}$ analysis of $\mathrm{CO}_{2}$ in air or pure $\mathrm{CO}_{2}$ gases (Brand et al., 2009b). Unfortunately, the comparison based on the new combustion experiments made at CIC could not include $\delta^{2} \mathrm{H}-\mathrm{CH}_{4}$ because the system was not capable to process $\mathrm{CH}_{4}$ samples large enough to provide sufficient amounts of $\mathrm{H}_{2} \mathrm{O}$.

We use the indices $\mathrm{CIC}-$ old for experiments made at CIC and published by Sperlich et al. (2012) and CIC-new for the new combustion experiments at CIC. We use the index MPI-BGC* for the analysis at MPI-BGC of $\mathrm{CO}_{2}$ samples that were combusted at $\mathrm{CIC}$ and $\mathrm{MPI}-\mathrm{BGC}$ for the calibrations of the two $\mathrm{CH}_{4}$ gases from CIC using the analytical methods at MPI-BGC presented above (Sect. 2.2 and 2.3).

\section{Results}

\subsection{Results for primary $\mathrm{CH}_{4}$ gas calibrations on the international VSMOW and VPDB isotope scales}

We performed 214 repetitive calibration measurements for Megan and Merlin for $\delta^{2} \mathrm{H}-\mathrm{CH}_{4}$ and $\delta^{13} \mathrm{C}-\mathrm{CH}_{4}$; the results are given in Table 3. Megan and Merlin have $\delta^{2} \mathrm{H}-\mathrm{CH}_{4}$ values of $-168.1 \pm 0.7 \%$ and $-165.7 \pm 0.7 \%$, respectively, and $\delta^{13} \mathrm{C}_{-}-\mathrm{CH}_{4}$ values of $-40.76 \pm 0.04$ and $-39.06 \pm 0.02 \%$, respectively. Both the $\delta^{2} \mathrm{H}-\mathrm{CH}_{4}$ and $\delta^{13} \mathrm{C}-\mathrm{CH}_{4}$ values are typical for fossil $\mathrm{CH}_{4}$ (e.g. Quay et al., 1999; Mikaloff Fletcher et al., 2004). The $\delta^{13} \mathrm{C}-\mathrm{CH}_{4}$ uncertainty in Megan and Merlin increases to 0.16 and $0.15 \%$, respectively, when the suggested uncertainty of $0.15 \%$ o for LSVEC is taken into account in the traceability chain (Qi et al., 2016; Schimmelmann et al., 2016). However, we will use the uncertainty budget without the new uncertainty for LSVEC for the evaluation of internal results.

\subsection{Results for secondary $\mathrm{CH}_{4}$ gas calibrations against primary $\mathrm{CH}_{4}$ gases}

We made a total of 260 calibration measurements for the secondary $\mathrm{CH}_{4}$ gases for $\delta^{2} \mathrm{H}-\mathrm{CH}_{4}$ and $\delta^{13} \mathrm{C}-\mathrm{CH}_{4}$. Altogether, the secondary $\mathrm{CH}_{4}$ gases cover a large range in $\delta^{2} \mathrm{H}$ $\left(-320\right.$ to $+36 \%$ ) and $\delta^{13} \mathrm{C}(-70$ to $-39 \%)$, where the former was achieved by spiking some of the gases with pure $\mathrm{CH}_{3} \mathrm{D}$. The results for secondary $\mathrm{CH}_{4}$ gas calibrations are shown in Table 3, including the uncertainties of the full traceability chain. We found typical uncertainties on the order of $0.8 \%$ of $\delta^{2} \mathrm{H}-\mathrm{CH}_{4}$ calibrations and on the order of 0.07 and $0.17 \%$ o for $\delta^{13} \mathrm{C}-\mathrm{CH}_{4}$ calibrations, where the latter includes the uncertainty of $0.15 \%$ in LSVEC.

\subsection{Results from the comparison between CIC and MPI-BGC}

Our comparison results for $\delta^{13} \mathrm{C}-\mathrm{CH}_{4}$ show overall agreement within the uncertainties of the traceability chains (Table 4$)$. The $\delta^{13} \mathrm{C}$ results from the previous and the new com- 
Table 3. Results of $\mathrm{CH}_{4}$ isotope calibrations. Gas names as used in main text and their function as primary or secondary $\mathrm{CH}_{4}$ are shown in column 1 and 2 respectively. All uncertainty estimates include the full traceability chain (Sect. 2.4). Note that we provide uncertainty estimates for $\delta^{13} \mathrm{C}-\mathrm{CH}_{4}$ without and with the uncertainty of $0.15 \%$ in LSVEC in column 6 and 7 respectively. Martha-1 and Mike-1 were intermittent gases and used to produce Martha-2 and Mike-2.

\begin{tabular}{|c|c|c|c|c|c|c|}
\hline Gas name & Function & $n\left(\delta^{2} \mathrm{H}\right)$ & $\delta^{2} \mathrm{H}-\mathrm{CH}_{4}[\% o]$ & $n\left(\delta^{13} \mathrm{C}\right)$ & $\begin{array}{r}\delta^{13} \mathrm{C}-\mathrm{CH}_{4}[\% \circ] \\
u_{\mathrm{LSVEC}}= \pm 0.00 \%\end{array}$ & $\begin{array}{r}\delta^{13} \mathrm{C}-\mathrm{CH}_{4}[\% o] \\
u_{\mathrm{LSVEC}}= \pm 0.15 \% o\end{array}$ \\
\hline Megan & primary & 116 & $-168.1 \pm 0.7$ & 15 & $-40.76 \pm 0.04$ & $-40.76 \pm 0.16$ \\
\hline Merlin & primary & 51 & $-165.7 \pm 0.7$ & 32 & $-39.06 \pm 0.02$ & $-39.06 \pm 0.15$ \\
\hline Martha-1 & secondary & 15 & $-176.6 \pm 0.8$ & 10 & $-48.84 \pm 0.07$ & $-48.84 \pm 0.17$ \\
\hline Martha-2 & secondary & 9 & $+36.2 \pm 1.0$ & 19 & $-48.92 \pm 0.06$ & $-48.92 \pm 0.16$ \\
\hline Mike-1 & secondary & 12 & $+44.5 \pm 0.9$ & 8 & $-40.79 \pm 0.09$ & $-40.79 \pm 0.17$ \\
\hline Mike-2 & secondary & 15 & $-80.3 \pm 0.5$ & 13 & $-42.76 \pm 0.05$ & $-42.76 \pm 0.16$ \\
\hline Merida & secondary & 12 & $-171.7 \pm 0.9$ & 13 & $-60.39 \pm 0.09$ & $-60.39 \pm 0.18$ \\
\hline Melly & secondary & 19 & $-177.5 \pm 0.7$ & 15 & $-70.04 \pm 0.07$ & $-70.04 \pm 0.17$ \\
\hline Minion & secondary & 12 & $-182.7 \pm 0.8$ & 15 & $-58.19 \pm 0.05$ & $-58.19 \pm 0.16$ \\
\hline Merkur & secondary & 15 & $-195.8 \pm 0.9$ & 19 & $-43.05 \pm 0.04$ & $-43.03 \pm 0.16$ \\
\hline Fossil & secondary & 15 & $-171.9 \pm 0.9$ & 16 & $-39.71 \pm 0.08$ & $-39.71 \pm 0.17$ \\
\hline Biogenic & secondary & 25 & $-319.8 \pm 0.8$ & 10 & $-56.60 \pm 0.07$ & $-56.60 \pm 0.17$ \\
\hline
\end{tabular}

bustion experiments measured at CIC differ by -0.03 and $-0.06 \%$ o $\left(\delta_{\mathrm{CIC}-\text { new }}-\delta_{\mathrm{CIC}-\text { old }}\right)$ for Fossil and Biogenic, respectively, which is within the uncertainty of the full traceability chain and furthermore within the system reproducibility as stated in Sperlich et al. (2012). The $\delta^{13} \mathrm{C}$ differences between the results from the new combustion experiments measured at MPI-BGC* and at CIC $\left(\delta_{\text {MPI-BGC }}{ }^{*}-\right.$ $\left.\delta_{\mathrm{CIC}-\text { new }}\right)$ are $0.10 \%$ for Fossil and $0.11 \%$ for Biogenic, respectively, and agree well within the combined uncertainty of both methods. Table 4 shows even better agree-

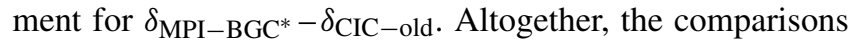
highlight the reproducibility of $\mathrm{CH}_{4}$ combustion experiments at CIC and the comparability of $\delta^{13} \mathrm{C}$ measurements in the combustion-derived $\mathrm{CO}_{2}$ at both laboratories.

When comparing the $\delta^{13} \mathrm{C}$ results from the new calibrations at MPI-BGC to the results based on combustion experiments at CIC, the results from MPI-BGC appear slightly more depleted in $\delta^{13} \mathrm{C}$ for both Fossil and Biogenic in all comparisons (Table 4). We find the smallest $\delta^{13} \mathrm{C}$ differences between $\delta_{\text {MPI-BGC }}$ and $\delta_{\text {CIC-new }}$, accounting for -0.08 and $-0.09 \%$ for Fossil and Biogenic respectively. The respective differences increase to -0.18 and $-0.20 \%$ o between $\delta_{\text {MPI-BGC }}$ and $\delta_{\text {MPI-BGC* }}$. It is important to note that only the difference found in Biogenic between $\delta_{\text {MPI-BGC }}$ and $\delta_{\text {MPI-BGC* }}$ is outside of the sum of the uncertainties (Table 4). In contrast, we find excellent agreement in all comparisons when the uncertainty of $0.15 \%$ in LSVEC is taken into account. Table 4 also shows excellent agreement in the determination of the differences between Fossil and Biogenic in all $\delta^{13} \mathrm{C}$ measurements, which is an important quantity for the evaluation of scale compression.

Comparing the results for $\delta^{2} \mathrm{H}-\mathrm{CH}_{4}$ between CIC and MPI-BGC shows overall agreement (Table 5). The differences we find in the $\delta^{2} \mathrm{H}-\mathrm{CH}_{4}$ calibrations between Sperlich et al. (2012) and MPI-BGC $\left(\delta_{\mathrm{MPI}-\mathrm{BGC}}-\delta_{\mathrm{CIC}-\text { old }}\right)$ are -1.8 and $-2.4 \%$ for Fossil and Biogenic respectively. Albeit it is slightly larger than the sum of the uncertainties of the measurements at CIC and MPI-BGC for Biogenic, the difference in Fossil is just within the uncertainties of the two methods. Note that the isotopic difference Fossil-Biogenic is homogenously resolved with $147.9 \%$ at MPI-BGC and $147.3 \%$ at CIC respectively.

\subsection{Results of $\delta^{2} \mathrm{H}-\mathrm{CH}_{4}$ and $\delta^{13} \mathrm{C}-\mathrm{CH}_{4}$ measurements in synthetic $\mathrm{CH}_{4}$-in-air standards to determine compatibility between the propagated isotope scale from IMAU and JRAS-M16 at MPI-BGC}

The isotopic difference $\left(\delta_{i \text { SAAC }}-\delta_{\text {pure }}\right)$ is shown in Table 6 and indicates the offset between the scale that was propagated from IMAU to MPI-BGC (Sect. 2.8) and the new synthetic $\mathrm{CH}_{4}$-in-air standards (JRAS-M16), assuming no isotope fractionation during the dilution process. Our experiments show excellent agreement for $\delta^{13} \mathrm{C}-\mathrm{CH}_{4}$ with an average difference of $+0.03 \pm 0.10 \%$, thus confirming that the propagated scale from IMAU was already very close to the newly determined scale anchor for $\delta^{13} \mathrm{C}-\mathrm{CH}_{4}$. For unknown reasons, the $\delta^{13} \mathrm{C}-\mathrm{CH}_{4}$ measurements of Melly, Fossil and Biogenic show a larger discrepancy between the two methods. Because the discrepancy for Biogenic exceeds the measurement uncertainty by a factor of 3 , we have excluded this result from the determination of the laboratory offset. The values for Melly and Fossil are within two uncertainties and are therefore included. For $\delta^{2} \mathrm{H}-\mathrm{CH}_{4}$ a systematic offset of $+4.2 \pm 1.2 \%$ is found, confirming that the calibration of Carina- 1 and hence the scale propagation from IMAU to MPI-BGC is flawed by an artefact. Obviously, 
Table 4. Results for comparison in $\delta^{13} \mathrm{C}$ between CIC and MPI-BGC. Indices of the header are explained in Sect. 2.9 of the main text. The CIC data are corrected for the offset in RM 8563 (Coplen et al., 2006b) and scale compression effects. They are furthermore presented with revised uncertainties to include the full traceability chain (Sect. 2.4). The uncertainties of the full traceability chains with the recently suggested uncertainty in LSVEC of $0.15 \%$ are shown in brackets. The $\delta^{13} \mathrm{C}_{\mathrm{MPI}-\mathrm{BGC}}$ measurements used a system that is virtually unaffected by scale compression (Ghosh et al., 2005) and a WS calibration that is based on NBS 19 as the only CRM; therefore, the $\delta^{13} \mathrm{C}_{\mathrm{MPI}-\mathrm{BGC}}{ }^{*}$ data do not suffer from the uncertainty in LSVEC. The difference Fossil-Biogenic can be used to compare scale compression effects between the respective methods.

\begin{tabular}{lrrrr}
\hline Gas name & ${ }^{13} \mathrm{C}_{\mathrm{CIC}-\text { old }}[\%$ o & $\delta^{13} \mathrm{C}_{\mathrm{CIC}-\text { new }}[\%$ o & ${ }^{13} \mathrm{C}_{\mathrm{MPI}-\mathrm{BGC}}[\%$ o $]$ & $\delta^{13} \mathrm{C}_{\mathrm{MPI}-\mathrm{BGC}}[\%$ o $]$ \\
\hline Fossil & $-39.60 \pm 0.07(0.17)$ & $-39.63 \pm 0.14(0.20)$ & $-39.53 \pm 0.11$ & $-39.71 \pm 0.08(0.17)$ \\
Biogenic & $-56.45 \pm 0.10(0.18)$ & $-56.51 \pm 0.08(0.17)$ & $-56.40 \pm 0.04$ & $-56.60 \pm 0.07(0.17)$ \\
Fossil-Biogenic & 16.85 & 16.88 & 16.87 & 16.89 \\
\hline
\end{tabular}

Carina-2 would have been a closer choice as scale anchor for $\delta^{2} \mathrm{H}-\mathrm{CH}_{4}$ (Table 2).

\section{Discussion}

\subsection{Discussion on the experimental artefact elimination during $\delta^{2} \mathrm{H}-\mathrm{CH}_{4}$ and $\delta^{13} \mathrm{C}-\mathrm{CH}_{4}$ calibrations in primary and secondary $\mathrm{CH}_{4}$ gases}

We present $\delta^{2} \mathrm{H}$ and $\delta^{13} \mathrm{C}$ calibrations in pure $\mathrm{CH}_{4}$ gases against CRMs, WSs and other $\mathrm{CH}_{4}$ gases. Samples and reference materials were always analysed in the same analytical systems, thereby complying with the PIT as much as possible. The only limitation of the PIT is due to the chemical difference between unknown samples $\left(\mathrm{CH}_{4}\right)$ and the known reference materials (carbonates, $\mathrm{H}_{2} \mathrm{O}$ ) used for anchoring the $\mathrm{CH}_{4}$ gases to the respective isotope scales. In order to calibrate the primary $\mathrm{CH}_{4}$ gases accurately, we need to exclude or eliminate material- and method-specific errors (IAEA, 2003), which we discuss in the following.

Quantitative oxidation of $\mathrm{CH}_{4}$ during $\delta^{13} \mathrm{C}-\mathrm{CH}_{4}$ analysis requires high reaction temperatures (e.g. Dumke et al., 1989). A major complication during $\delta^{13} \mathrm{C}-\mathrm{CH}_{4}$ analysis arises when oxidation yields are significantly lower than $100 \%$ (Merritt et al., 1995; Fig. 4 in Sperlich et al., 2012). $\mathrm{CH}_{4}$ is a potent source of protonation in the IRMS ion source (Anicich, 1993). Introducing unconverted $\mathrm{CH}_{4}$ together with the $\mathrm{CH}_{4}$-derived $\mathrm{CO}_{2}$ sample into the IRMS results in the formation of $\mathrm{CO}_{2} \mathrm{H}^{+}$in the ion source, which produces an isobaric interference on the $m / z 45$ trace, where the $\delta^{13} \mathrm{C}$ signal is measured. This artefact can be prevented when $\mathrm{CO}_{2}$ and $\mathrm{CH}_{4}$ are separated after the oxidation, which we achieve with the post-combustion chromatographic column in both the EA-IRMS system (Sect. 2.3) and iSAAC (Sect. 2.6). Note how this effect would cause an accuracy shift towards more enriched $\delta{ }^{13} \mathrm{C}-\mathrm{CH}_{4}$ values predominantly during primary $\mathrm{CH}_{4}$ gas calibrations, because $\mathrm{CH}_{4}$ samples would be affected by $\mathrm{CO}_{2} \mathrm{H}^{+}$formation in the ion source while the analysis of the used CRMs would not.
We carefully checked the completeness of $\mathrm{CH}_{4}$ conversion (EA-IRMS and TC/EA-IRMS) by monitoring for residual $\mathrm{CH}_{4}$ with the IRMS instruments. In the ion source, $\mathrm{CH}_{4}$ molecules are subject to fragmentation and re-combination processes, resulting in $\mathrm{CH}_{4}$-typical mass spectra during mass abundance scans in the IRMS (Brunnée and Voshage, 1964). The strongest $\mathrm{CH}_{4}$-specific signal occurs on the $\mathrm{m} / z, 15$ trace $\left(\mathrm{CH}_{3}^{+}\right)$, which makes the $m / z 15$ signal a good indicator for incomplete $\mathrm{CH}_{4}$ conversion (Sperlich et al., 2012). The $\mathrm{CH}_{4}^{+}$signal at $\mathrm{m} / \mathrm{z} 16$ is not suitable for $\mathrm{CH}_{4}$ quantification due to the interference with the $\mathrm{O}^{+}$signal from $\mathrm{CO}_{2}^{+}$ fragmentation. We tune the $\mathrm{m} / \mathrm{z} 44$ collector of the IRMS to monitor the $m / z \quad 15$ trace during the analysis of a $\mathrm{CH}_{4}$ sample and find an amplitude of $0.12 \mathrm{mV}$. From Sperlich et al. (2012) we estimate that about $40 \%$ of the total $\mathrm{CH}_{4}$ signal in a mass abundance scan is recorded on $m / z$ 15. The total $\mathrm{CH}_{4}$ signal in the mass abundance scan would therefore amount to $\sim 0.3 \mathrm{mV}$, which we can compare to the $\sim 7000 \mathrm{mV}$ on $\mathrm{m} / \mathrm{z} 44$ from a typical $\mathrm{CH}_{4}$ injection into the EA-IRMS (e.g. Fig. 5). This approximation suggests a $\mathrm{CH}_{4}$ oxidation efficiency of $>99.9 \%$. An analogue experiment on the TC/EA-IRMS system (Sect. 2.2) shows a conversion efficiency of $\mathrm{CH}_{4}$ of $>99.9 \%$ as well. Because the ionisation energy of $\mathrm{CH}_{4}$ is comparable to that of both $\mathrm{CO}_{2}$ and $\mathrm{H}_{2}$, we can ignore this effect in the above determinations. Therefore, we conclude that the $\mathrm{CH}_{4}$ conversion at MPI-BGC is complete and that we can rule out incomplete conversion as source for measurement errors.

It has been demonstrated that the introduction of carbonates into the high-temperature oxidation furnace of the EA-IRMS yields a high $\mathrm{CO}_{2}$ conversion rate and $\delta^{13} \mathrm{C}$ results of high precision and accuracy (Coplen et al., 2006b). In order to test for the completeness of carbonate digestion, we added tungsten trioxide $\left(\mathrm{WO}_{3}\right)$ to some of the carbonate samples during weighing (about $1: 1$ by weight). The goal of this experiment is to increase the instantaneous reaction temperature and to provide additional oxygen during the liberation of $\mathrm{CO}_{2}$ from different carbonates. While the addition of $\mathrm{WO}_{3}$ had no effect on the analysis of $\mathrm{CaCO}_{3}$ and $\mathrm{Li}_{2} \mathrm{CO}_{3}$, it improved the peak shape during $\mathrm{BaCO}_{3}$ analysis (Table 2). 
Table 5. Comparison of $\delta^{2} \mathrm{H}$ results between CIC and MPI-BGC. Indices of the header are explained in Sect. 2.9 of the main text. The uncertainty of all data includes the full traceability chain (Sect. 2.4), which includes revised uncertainties of the CIC data (Sect. 2.9). The difference Fossil - Biogenic allows us to compare scale compression effects between both methods.

\begin{tabular}{lrr}
\hline Gas name & $\delta^{2} \mathrm{H}_{\mathrm{CIC}-\text { old }}[\%$ o] & $\delta^{2} \mathrm{H}_{\mathrm{MPI}-\mathrm{BGC}[\% \text { [ ] }}$ \\
\hline Fossil & $-170.1 \pm 0.9$ & $-171.9 \pm 0.9$ \\
Biogenic & $-317.4 \pm 0.9$ & $-319.8 \pm 0.8$ \\
Fossil-Biogenic & 147.3 & 147.9 \\
\hline
\end{tabular}

However, it did not impact on its $\delta^{13} \mathrm{C}$. We conclude that the carbonate digestion is not limited by either temperature or oxygen availability and omitted the addition of $\mathrm{WO}_{3}$ in further reactions. Note that the accurate analysis of carbonates is critical for accurate $\mathrm{CH}_{4}$ calibrations, even if $\mathrm{CH}_{4}$ injections themselves are not compromised.

A considerable advantage of the conversion of carbonates in the high-temperature oxidation furnace of the EA-IRMS over other methods (e.g. acid reaction) is that the oxygen isotopic composition is homogenised for all samples. This balances the ${ }^{17} \mathrm{O}$ correction, which accounts for the isobaric interference between $\delta^{13} \mathrm{C}-\mathrm{CO}_{2}$ and $\delta^{17} \mathrm{O}-\mathrm{CO}_{2}$ on $\mathrm{m} / z$ 45. The ${ }^{17} \mathrm{O}$ correction is statistically dependent on the $\delta^{18} \mathrm{O}-\mathrm{CO}_{2}$ of each individual sample. Hence, any uncertainty arising from the ${ }^{17} \mathrm{O}$ correction during the calculation of $\delta^{13} \mathrm{C}$ values from $m / z 45$ ion currents tends to cancel out. The applied ${ }^{17} \mathrm{O}$ correction is a function built into the evaluation software of the IRMS. The algorithm and ratio assumptions are based on Assonov and Brenninkmeijer (2001). The same technique had been used to revise the VPDB scale by adding LSVEC as a second scaling point (Coplen et al., 2006b).

The EA-IRMS analysis of carbonates includes a wellcharacterised blank contribution that is due to the carbon impurities within the tin capsules that are used for carbonate analyses (Werner et al., 1999). In contrast, no such blank is expected when samples are analysed without tin capsules, as would be the case for gaseous $\mathrm{CH}_{4}$ samples. While we did not observe a significant $\delta^{13} \mathrm{C}$ difference when tin capsules were added to $\mathrm{CH}_{4}$ injections and the $\delta^{13} \mathrm{C}$ bias was subsequently corrected for or when the $\delta^{13} \mathrm{C}-\mathrm{CH}_{4}$ analysis was performed without tin capsules. We continuously added the tin capsules to each $\delta^{13} \mathrm{C}-\mathrm{CH}_{4}$ analysis and applied the routine blank correction to all measurements in compliance with the PIT between analyses of carbonate reference materials and $\mathrm{CH}_{4}$ samples.

For $\delta^{2} \mathrm{H}$ analyses, we chose an analogue approach and process both $\mathrm{H}_{2} \mathrm{O}$ and $\mathrm{CH}_{4}$ using the high-temperature reactor of the TC/EA-IRMS system. Possible artefacts can arise mainly from the stronger surface activities of $\mathrm{H}_{2} \mathrm{O}$ vs. $\mathrm{CH}_{4}$ prior to the conversion to $\mathrm{H}_{2}$ (and $\mathrm{CO}$ or carbon). $\mathrm{H}_{2} \mathrm{O}$ injections can lead to memory effects, which need to be taken into
Table 6. Differences in $\delta^{2} \mathrm{H}-\mathrm{CH}_{4}$ and $\delta^{13} \mathrm{C}-\mathrm{CH}_{4}$ between primary/secondary $\mathrm{CH}_{4}$ gas calibrations and $i \mathrm{SAAC}$ measurements of the synthetic $\mathrm{CH}_{4}$-in-air standards using the scale anchor based on Carina-1. Differences are calculated as $\delta_{i \mathrm{SAAC}}-\delta_{\text {pure }}$. The bottom line shows the average and the standard deviation $(1 \sigma)$ of considered differences, excluding the value of Biogenic $\left(^{\circ}\right)$ as described in main text.

\begin{tabular}{lrr}
\hline Gas name & $\Delta \delta^{2} \mathrm{H}-\mathrm{CH}_{4}[\%$ o] & $\Delta \delta^{13} \mathrm{C}-\mathrm{CH}_{4}[\%$ o] \\
\hline Megan & 3.9 & 0.05 \\
Merlin & 5.6 & -0.04 \\
Minion & 2.7 & -0.05 \\
Melly & 4.3 & 0.13 \\
Mike-1 & 5.7 & -0.03 \\
Martha-1 & 3.2 & -0.06 \\
Fossil & 5.1 & 0.19 \\
Biogenic & 3.0 & $0.31\left(^{\circ}\right)$ \\
Average & $+4.2 \pm 1.2$ & $+0.03 \pm 0.10$ \\
\hline
\end{tabular}

account in $\delta^{2} \mathrm{H}-\mathrm{H}_{2} \mathrm{O}$ and subsequent $\delta^{2} \mathrm{H}-\mathrm{CH}_{4}$ analyses, either by discarding initial injections or making appropriate corrections (Werner and Brand, 2001). $\mathrm{H}_{2} \mathrm{O}$ injections produced highest $\mathrm{H}_{2}$ yields and stable $\delta^{2} \mathrm{H}-\mathrm{H}_{2} \mathrm{O}$ values at reactor temperatures of $1450{ }^{\circ} \mathrm{C}$. Therefore we kept the reactor at $1450^{\circ} \mathrm{C}$ during all calibration measurements. In addition, we found a minor dependence of $\delta^{2} \mathrm{H}-\mathrm{H}_{2} \mathrm{O}$ on the septum temperature. We experimentally determined a septum temperature of $130^{\circ} \mathrm{C}$ at which the effect on $\delta^{2} \mathrm{H}-\mathrm{H}_{2} \mathrm{O}$ was insignificant and kept the septum at $130^{\circ} \mathrm{C}$ during all calibrations. We describe the experiments on reactor temperature and septum temperature in Appendix A in more detail. Note that it is essential to exclude systematic, material-specific errors to make $\mathrm{H}_{2} \mathrm{O}$ and $\mathrm{CH}_{4}$ reactions directly comparable for $\delta^{2} \mathrm{H}$ calibration. Based on these experiments we conclude that the $\delta^{2} \mathrm{H}-\mathrm{CH}_{4}$ calibrations do not contain measurement errors introduced by bracketing $\delta^{2} \mathrm{H}-\mathrm{H}_{2} \mathrm{O}$ analyses.

\subsection{Discussion of the comparison between CIC and MPI-BGC}

We compare the results of $\delta^{2} \mathrm{H}-\mathrm{CH}_{4}$ and $\delta^{13} \mathrm{C}-\mathrm{CH}_{4}$ calibrations achieved by the two independent methods from CIC and MPI-BGC in Tables 4 and 5. Note that the verification of the principle calibration method (MPI-BGC) by an independent method (CIC) is required for the preparation of QCMs when CRMs are not available (IAEA, 2003). The comparison between CIC and MPI-BGC is to some degree representative of the situation of the community analysing atmospheric $\delta^{2} \mathrm{H}-\mathrm{CH}_{4}$ and $\delta^{13} \mathrm{C}-\mathrm{CH}_{4}$ without access to international reference air but locally produced or propagated standard gases.

Even though there is no significant difference between the intercomparison results for $\delta^{13} \mathrm{C}-\mathrm{CH}_{4}$, and the difference in $\delta^{2} \mathrm{H}-\mathrm{CH}_{4}$ is rather small, there seems to be a systematic pattern that the samples combusted at CIC are generally more 
enriched in both $\delta^{2} \mathrm{H}$ and $\delta^{13} \mathrm{C}$ (Tables 4 and 5). The cause for this offset is not yet fully understood but will be discussed in more detail. The $\delta^{13} \mathrm{C}-\mathrm{CH}_{4}$ calibrations presented in Table 4 were made on three different IRMS systems with three different working standards. All $\delta^{13} \mathrm{C}$ measurements were corrected for potential scale compression effects, except from the MPI-BGC* analyses, which were made on an IRMS system specifically tuned to render scale compression effects for $\delta^{13} \mathrm{C}$, as demonstrated by Ghosh et al. (2005). Because the difference in $\delta^{13} \mathrm{C}$ between Fossil and Biogenic is remarkably well resolved in all comparison measurements (Table 4), we conclude that our $\delta^{13} \mathrm{C}$ comparison does not suffer from a significant scale compression error. Rather, the difference in $\delta^{13} \mathrm{C}$ between the methods seems related to the method of $\mathrm{CH}_{4}$ conversion. In principle, incomplete $\mathrm{CH}_{4}$ combustion in the experiments at CIC would create a $\delta^{13} \mathrm{C}$ pattern where the affected experiments appeared more enriched in $\delta^{13} \mathrm{C}$. This is because the remaining $\mathrm{CH}_{4}$ fraction in the combustion-derived $\mathrm{CO}_{2}$ gas would be introduced into the dual-inlet IRMS together with the $\mathrm{CO}_{2}$, and form $\mathrm{CO}_{2} \mathrm{H}^{+}$ ions, which creates an artefact on $m / z 45$ (Sect. 4.1). However, we carefully tested every sample for residual $\mathrm{CH}_{4}$ and are confident that the $\mathrm{CH}_{4}$ combustions at CIC have been complete. Therefore, we cannot resolve this difference further.

We also observe a small $\delta^{2} \mathrm{H}-\mathrm{CH}_{4}$ offset between CIC and MPI-BGC. The $\delta^{2} \mathrm{H}$ measurements at CIC were made using combustion-derived $\mathrm{H}_{2} \mathrm{O}$ with two different methods (TC/EA-IRMS and CRDS). Moreover, the measurement procedures at CIC included WSs covering the full VSMOW/SLAP scale. In contast, the direct $\delta^{2} \mathrm{H}-\mathrm{CH}_{4}$ analysis of the secondary $\mathrm{CH}_{4}$ gases at MPI-BGC was performed as a one-point calibration against Megan or Merlin with a $\delta^{2} \mathrm{H}-\mathrm{CH}_{4}$ similar to that of Fossil (Table 3). Please note that $\delta^{2} \mathrm{H}$ scale compression often arises during the analysis of $\mathrm{H}_{2} \mathrm{O}$ because it interacts with all sorts of surfaces in the analytical system. However, $\mathrm{CH}_{4}$ gas behaves very much like pure $\mathrm{H}_{2}$ in the high-temperature conversion system and a careful $\mathrm{H}_{3}^{+}$-factor determination often results in accurate isotopic distances. If the control of scale compression at MPI-BGC was limited due to the one-point calibration, we would expect the isotopic difference between Biogenic and Fossil to be smaller in the results from MPI-BGC than CIC. However, this is clearly not the case. The isotopic difference between Biogenic and Fossil $\left(\delta_{\text {Fossil }}-\delta_{\text {Biogenic }}\right)$ appears to be very similar in the calibrations of both laboratories with $147.3 \%$ at CIC and $147.9 \%$ at MPI-BGC, even showing a slightly larger difference at MPI-BGC (Table 5). Therefore, we are confident that the observed, small $\delta^{2} \mathrm{H}$ offset is not caused by scale compression effects in one of the laboratories. Moreover, the excellent agreement between the experimentally controlled scale compression at CIC and the method at MPI-BGC proves that the analysis at MPI-BGC is free of significant scale compression artefacts over the tested isotopic range of $\sim 150 \%$.
The comparisons show small differences in the calibration results, but we found no evidence that either one of the two analytical methods is more accurate. Note that the difference in both $\delta^{2} \mathrm{H}-\mathrm{CH}_{4}$ and $\delta^{13} \mathrm{C}-\mathrm{CH}_{4}$ exceeds the compatibility goal of 1 and $0.02 \%$ o by a factor of 2 to 10 respectively (WMO, 2014). We interpret the results of this comparison to reflect calibration differences between laboratories that are to be expected, when CRMs are not available. Finally, we conclude that our new method is as capable to calibrate $\mathrm{CH}_{4}$ gases to the international isotope scales and that it is as accurate as the method presented by Sperlich et al. (2012). However, we think that our new methods are more suitable for the task to produce and maintain a suite of calibration gases for the following reasons.

- The methods at MPI-BGC are more time efficient than the method of Sperlich et al. (2012). While the new methods at MPI-BGC can be used to calibrate an entire suite of $\mathrm{CH}_{4}$ gases within a relatively short time, the method of Sperlich et al. (2012) is capable of processing only one sample per day.

- The new MPI-BGC methods are based on continuousflow IRMS and follow the PIT to the highest possible degree. In comparison, the method of Sperlich et al. (2012) is based on the combustion of $\mathrm{CH}_{4}$ in an offline reactor, which requires re-oxidation after every sample and partial dismantling of the system to retrieve the sample for isotopic analysis. Because the analytical system at CIC could theoretically be at a different state for every sample (oxidation state, air leak rate) and because the system at CIC does not allow us to compare two $\mathrm{CH}_{4}$ gases directly against each other, the methods at MPI-BGC are superior in the ability to fulfil the PIT. Even though the method at CIC proved to be very reproducible, we cannot rule out that a variation in the oxidation state of the reactor or an undetected air leakage into the system would affect the analysis of some $\mathrm{CH}_{4}$ samples more than others. Because fulfilling the PIT is of paramount importance for isotope ratio analysis (e.g. Werner and Brand, 2001; Schimmelmann et al., 2016), we believe the method at MPI-BGC is less vulnerable to measurement errors in future calibrations.

\subsection{Discussion on the compatibility between the scale anchors for $\delta^{2} \mathrm{H}-\mathrm{CH}_{4}$ and $\delta^{13} \mathrm{C}-\mathrm{CH}_{4}$ as propagated from IMAU to MPI-BGC and JRAS-M16}

We interpret the excellent agreement between the $\delta^{13} \mathrm{C}$ and $\mathrm{CH}_{4}$ calibrations in Carina-1 and Carina-2 from IMAU (Table 2) that both gases are precisely referenced and suitable for scale propagation from IMAU to MPI-BGC. The synthetic $\mathrm{CH}_{4}$-in-air standards were analysed on $i \mathrm{SAAC}$ for $\delta^{2} \mathrm{H}-\mathrm{CH}_{4}$ and $\delta^{13} \mathrm{C}-\mathrm{CH}_{4}$ and their isotope values were assigned using a WS that was calibrated against Carina-1. We can then 
interpret the $\delta^{13} \mathrm{C}$ difference between the $i \mathrm{SAAC}$ measurement and the calibrated synthetic $\mathrm{CH}_{4}$-in-air standards of $+0.03 \pm 0.10 \%$ as an accurate estimate for the calibration offset between the propagated scale anchor at MPI-BGC and the newly developed JRAS-M16.

Unfortunately, the situation is currently less straightforward for $\delta^{2} \mathrm{H}-\mathrm{CH}_{4}$. The two WSs Carina-1 and Carina-2 were calibrated at IMAU with a difference in $\delta^{2} \mathrm{H}-\mathrm{CH}_{4}$ of $2.8 \%$ that was insignificant at the time (Table 2). Because Carina- 1 and Carina-2 appear indistinguishable in $\delta^{2} \mathrm{H}-\mathrm{CH}_{4}$ when compared to $i \mathrm{SAAC}$ with a measurement precision for $\delta^{2} \mathrm{H}-\mathrm{CH}_{4}$ of $1.0 \%$ (Sect. 2.6), we cannot determine the laboratory offset with the same certainty as for ${ }^{13} \mathrm{C}_{-} \mathrm{CH}_{4}$. If either Carina-1 or Carina-2 were representative for the calibrations at IMAU, the $\delta^{2} \mathrm{H}-\mathrm{CH}_{4}$ offset between the laboratories would amount to $+4.2 \pm 1.2$ or $+1.4 \pm 1.2 \%$ o respectively. A further comparison that includes new measurements on the current system at IMAU is required to determine the offset $\delta^{2} \mathrm{H}-\mathrm{CH}_{4}$ accurately. This offset can be resolved, for example, when a set of synthetic $\mathrm{CH}_{4}$-in-air standards (JRAS-M16) is analysed at IMAU in future.

\subsection{Discussion on possible use of synthetic $\mathrm{CH}_{4}$-in-air standards in future}

We demonstrated the ability to test the compatibility between IMAU and MPI-BGC by comparing scale anchors that were previously propagated from IMAU to MPI-BGC to JRAS-M16 gases. Future developments include an interlaboratory comparison to test whether a dedicated set of our synthetic $\mathrm{CH}_{4}$-in-air standards (JRAS-M16) could provide a community anchor to the VPDB and VSMOW scales with documented accuracy. A further important test would be to determine to what extent the use of centrally calibrated standard gases could increase compatibility. A recent incidence provides a good example for the vulnerability of $\delta^{13} \mathrm{C}-\mathrm{CH}_{4}$ observations in the atmosphere without suitable m-RM.

LSVEC, the second CRM anchor to the VPDB scale, has recently been discovered to be less reliable than anticipated. Until further notice, LSVEC is suggested to be treated with an enhanced $\delta^{13} \mathrm{C}$ uncertainty of $0.15 \%$ o (S. Assonov, personal communication, 2016). It is important to appreciate that this uncertainty is fully added to the uncertainty of $\delta^{13} \mathrm{C}-\mathrm{CH}_{4}$ measurements, due to the similarity of LSVEC $\left(-46.6 \%\right.$ o) and tropospheric $\mathrm{CH}_{4}(-47.5 \%$ ) in $\delta^{13} \mathrm{C}$. That is, the new uncertainty of LSVEC contributes the largest component in the full error budget of $\delta^{13} \mathrm{C}-\mathrm{CH}_{4}$ analysis. Note that the suggested uncertainty of LSVEC is (i) on the order of the seasonal $\delta^{13} \mathrm{C}-\mathrm{CH}_{4}$ cycle in the Southern Hemisphere and (ii) a multiple of the analytical precision of laboratories monitoring $\delta^{13} \mathrm{C}-\mathrm{CH}_{4}$. If measurements of $\delta^{13} \mathrm{C}-\mathrm{CH}_{4}$ considered the new uncertainty for LSVEC, the significance of signals such as the seasonal variability in the Southern Hemisphere would be lost on the cost of a better representation of accuracy. Including the uncer- tainty of LSVEC may further impact on the compatibility between several laboratories and, for example, suggest an artificially imposed spatial $\delta^{13} \mathrm{C}-\mathrm{CH}_{4}$ gradient, based on calibration artefacts. We advocate the scientific gain when accuracy and compatibility are differentiated (WMO, 2014). The community benefits from a referencing method that enables a compatibility level that is smaller than the atmospheric $\delta^{13} \mathrm{C}-\mathrm{CH}_{4}$ signal to resolve spatiotemporal $\delta^{13} \mathrm{C}-\mathrm{CH}_{4}$ differences as primary goal. We think that establishing JRAS-M16 as community scale anchor could be a valuable step towards reaching this goal. As appropriate for any scale anchor that is intended to be usable for the whole community over long periods of time, the scale anchors will have to be re-calibrated frequently in order to detect possible drifts or to improve and correct previous assignments. The results of these efforts will be made available to the public at regular intervals.

We propose the distribution of JRAS-M16, a set of synthetic $\mathrm{CH}_{4}$-in-air standards in $5 \mathrm{~L}$ glass flasks. While two JRAS-M16 gases shall be used as calibration standard, an optional third JRAS-M16 gas can be used as unknown that is calibrated against the known JRAS-M16 gases as measurement control standard. This experiment would simulate the case when all participating laboratories measure the same sample directly against the same m-RM using the method that is otherwise applied to every sample in the respective laboratory and has the potential to determine the achievable compatibility. A further possibility to share the JRAS-M16 scale anchor would be to send cylinders with air-WSs to MPI-BGC for calibration. Because a dedicated target of this work is to achieve best possible accuracy with JRAS-M16, we provide the uncertainty of the full traceability chain. Once a new CRM has been found in replacement of LSVEC, the $\delta^{13} \mathrm{C}-\mathrm{CH}_{4}$ and the traceability chain of JRAS-M16 will be revised accordingly. This will also be made upon future CRM revisions or replacements.

\section{Conclusions}

The number of laboratories that measure isotope ratios of atmospheric $\mathrm{CH}_{4}$ is growing and combining data from multiple laboratories could enable new science and increasingly powerful analysis. However, merging data from multiple laboratories for analysis is currently hampered by the lack of reference materials that enable the community to produce a unified data set. To overcome this problem and to improve compatibility between laboratories, we produced synthetic $\mathrm{CH}_{4}$-in-air standards (JRAS-M16). We modified standard online IRMS techniques to calibrate pure $\mathrm{CH}_{4}$ gases for $\delta^{2} \mathrm{H}$ and $\delta^{13} \mathrm{C}$ on international VSMOW and VPDB isotope scales respectively. Because such instrumentation is available to many isotope laboratories, our technical modifications and experiments can be reproduced elsewhere. Eight of the calibrated $\mathrm{CH}_{4}$ gases were diluted with $\mathrm{CH}_{4}$-free air in $5 \mathrm{~L}$ glass flasks to produce synthetic $\mathrm{CH}_{4}$-in-air standards 
with known $\delta^{2} \mathrm{H}-\mathrm{CH}_{4}$ and $\delta^{13} \mathrm{C}-\mathrm{CH}_{4}$ values. These synthetic gas mixtures were then analysed on a newly developed system (iSAAC) to measure $\delta^{2} \mathrm{H}-\mathrm{CH}_{4}$ and $\delta^{13} \mathrm{C}-\mathrm{CH}_{4}$ in air samples. Hitherto, $i \mathrm{SAAC}$ used working standards as scale anchors for $\delta^{2} \mathrm{H}-\mathrm{CH}_{4}$ and $\delta^{13} \mathrm{C}-\mathrm{CH}_{4}$, which were calibrated at a partnering institute (IMAU). The history of the propagated isotope scales goes more than 2 decades back in time and includes the propagation between several laboratories. We determine $\delta^{2} \mathrm{H}-\mathrm{CH}_{4}$ and $\delta^{13} \mathrm{C}-\mathrm{CH}_{4}$ in our synthetic $\mathrm{CH}_{4}$-in-air standards using the scale anchor propagation from IMAU and compare the results with our calibration results for $\delta^{2} \mathrm{H}-\mathrm{CH}_{4}$ and $\delta^{13} \mathrm{C}-\mathrm{CH}_{4}$. We use this method to determine the $\delta^{13} \mathrm{C}-\mathrm{CH}_{4}$ offsets between the scale anchor that was propagated from IMAU and JRAS-M16, thereby providing a method to improve compatibility. Further comparisons are required to determine the offset for $\delta^{2} \mathrm{H}-\mathrm{CH}_{4}$.

We welcome other laboratories to further test our calibrations by analysing JRAS-M16 air sets, which will be available upon request. Another possibility could be to have cylinders with air-WSs sent to MPI-BGC for calibration using JRAS-M16 as scale anchor. JRAS-M16 may help laboratories to anchor $\delta^{2} \mathrm{H}-\mathrm{CH}_{4}$ and $\delta^{13} \mathrm{C}-\mathrm{CH}_{4}$ observations to unified community scale anchors. This might be a useful step towards reaching the compatibility goals between laboratories, leading to an improved understanding of atmospheric $\mathrm{CH}_{4}$. Future work includes a revision of the $\delta^{13} \mathrm{C}-\mathrm{CH}_{4}$ calibrations once the replacement for LSVEC is established. This will reduce the uncertainty of the $\delta^{13} \mathrm{C}^{-} \mathrm{CH}_{4}$ scale anchors significantly. The LSVEC replacement should extend to the $\delta^{13} \mathrm{C}$-depleted range of biogenic $\mathrm{CH}_{4}$ gases.

\section{Data availability}

The results of our final calibrations with the associated uncertainties of the full traceability chains are published as a Supplement to this paper. The supplementary data file also contains the revised calibrations of the data by Sperlich et al. (2012). These include corrections for the offset in RM8563 and for scale compression effect in the IRMS at CIC. 


\section{Appendix A: Experiments to enhance the performance of the analytical system for the calibration of $\delta^{2} \mathrm{H}-\mathrm{CH}_{4}$ with $\mathrm{H}_{2} \mathrm{O}$}

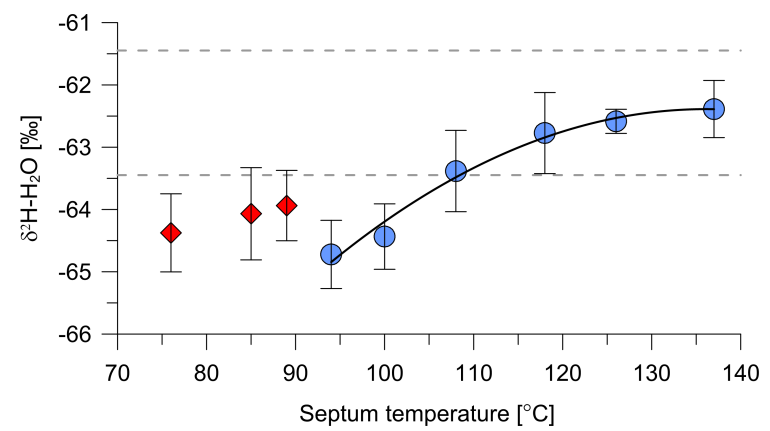

Figure A1. The $\delta^{2} \mathrm{H}$ variation of $\mathrm{H}_{2} \mathrm{O}$ injections with septum temperatures. Blue circles show average $\delta^{2} \mathrm{H}-\mathrm{H}_{2} \mathrm{O}$ values for septum temperatures above $90^{\circ} \mathrm{C}$, the black line is the quadratic polynomial fit to the data above $90^{\circ} \mathrm{C}$ while red diamonds display $\delta^{2} \mathrm{H}-\mathrm{H}_{2} \mathrm{O}$ values at septum temperatures below $90^{\circ} \mathrm{C}$. The error bars show $1 \sigma$ standard deviations and the grey-dashed lines indicate the typical precision limit of $1 \%$ for $\delta^{2} \mathrm{H}-\mathrm{H}_{2} \mathrm{O}$ analysis (Gehre et al., 2004) around the $\delta^{2} \mathrm{H}-\mathrm{H}_{2} \mathrm{O}$ value of the polynomial fit for the septum temperature of $130^{\circ} \mathrm{C}$ (set point during calibration experiments). The grey dashed lines show that our $\delta^{2} \mathrm{H}-\mathrm{H}_{2} \mathrm{O}$ analyses remain within a typical precision level as long as the septum temperature is controlled to $\sim 130 \pm 10^{\circ} \mathrm{C}$.

The injection of $\mathrm{H}_{2} \mathrm{O}$ samples into the reactor is critical because it is prone to isotopic fractionation (Werner and Brand, 2001). This fractionation is mainly caused by system memory due to adhesion of injected $\mathrm{H}_{2} \mathrm{O}$ to the reactor walls. The isotopic fractionation can be overcome by repetitive injections of $\mathrm{H}_{2} \mathrm{O}$ samples with identical isotopic composition, thereby overwriting the memory effect until it reaches a marginal level. For $\mathrm{H}_{2} \mathrm{O}$ analyses under constant analytical conditions (e.g. constant reactor temperature), the adhesion effect is a function mainly of the amount of injected $\mathrm{H}_{2} \mathrm{O}$ sample. Moreover, the effect on the isotopic composition scales with the isotopic difference between two consecutive samples (Gehre et al., 2004). Because there is no adhesion of the sample during $\mathrm{CH}_{4}$ analysis, this memory effect is most pronounced only during the analysis of $\mathrm{H}_{2} \mathrm{O}$ in our study. Subsequent $\mathrm{CH}_{4}$ analysis does not contribute to system memory but can still be affected by $\mathrm{H}_{2} \mathrm{O}$ desorption from internal surfaces of the analytical system. Therefore, memory effects of $\mathrm{H}_{2} \mathrm{O}$ can propagate into the $\mathrm{CH}_{4}$ calibrations. Memory effects are identified in a series of replicate $\mathrm{H}_{2} \mathrm{O}$ measurements and are corrected for by modelling the memory function as described in Gehre et al. (2004) and Brand et al. (2009a) on a routine basis, as our system has been used for isotope analysis of $\mathrm{H}_{2} \mathrm{O}$ samples for more than a decade. We conclude that our results are free of artefacts arising from sample memory.

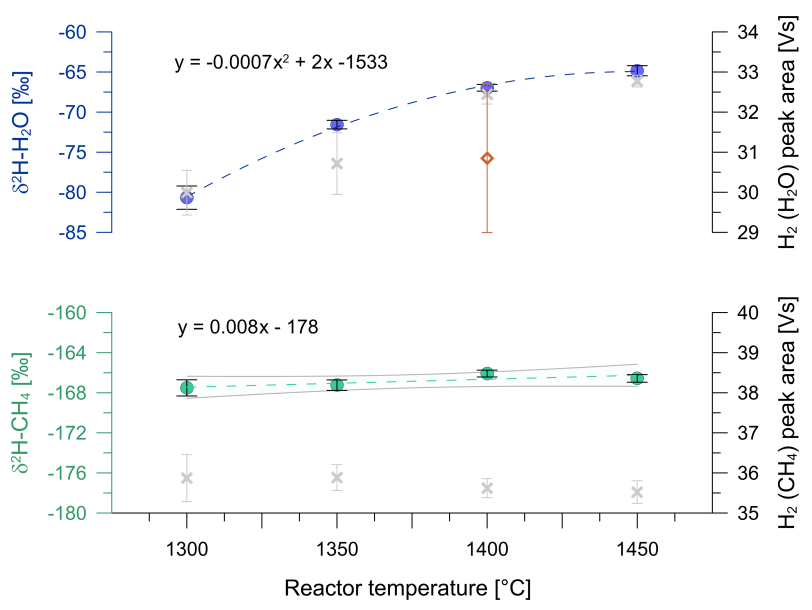

Figure A2. The dependence of $\delta^{2} \mathrm{H}$ and $\mathrm{H}_{2}$ peak areas of $\mathrm{H}_{2} \mathrm{O}$ and $\mathrm{CH}_{4}$ injections from reactor temperatures between 1300 and $1450{ }^{\circ} \mathrm{C}$. Top and bottom panels show $\mathrm{H}_{2} \mathrm{O}$ and $\mathrm{CH}_{4}$ experiments respectively. $\delta^{2} \mathrm{H}$ isotope ratios are shown in blue for $\mathrm{H}_{2} \mathrm{O}$ and green for $\mathrm{CH}_{4}$ and refer to the left-hand axes. Average $\mathrm{H}_{2}$ peak areas are indicated by grey crosses and refer to the right-hand axes. All error bars indicate the standard deviation. The red diamond shows the average peak area and the respective standard deviation including the outliers (see Appendix text). $Y$ axes ranges are matched between top and bottom panels to enable direct comparison of the temperature effect for $\mathrm{H}_{2} \mathrm{O}$ and $\mathrm{CH}_{4}$. Equations describe the fits in both panels, displayed by dashed lines. Continuous lines in the bottom panel indicate the $95 \%$ confidence interval of the linear fit.

Isotopic fractionation during the analysis of the reference waters can also be caused by insufficiently heated septa (Gehre et al., 2004). We injected 106 identical $\mathrm{H}_{2} \mathrm{O}$ samples while we increased the septum temperatures in nine steps from 76 to $137^{\circ} \mathrm{C}$. In general, we observed a $\delta^{2} \mathrm{H}$ enrichment with increasing septum temperature. A systematic increase of $\delta^{2} \mathrm{H}-\mathrm{H}_{2} \mathrm{O}$ with septum temperature is apparent above $90^{\circ} \mathrm{C}$ until $\delta^{2} \mathrm{H}-\mathrm{H}_{2} \mathrm{O}$ values plateau at septum temperatures around $130^{\circ} \mathrm{C}$ (Fig. A1, blue circles). The stabilising $\delta^{2} \mathrm{H}-\mathrm{H}_{2} \mathrm{O}$ at high temperatures suggests quantitative $\mathrm{H}_{2} \mathrm{O}$ processing without significant isotope fractionation, in line with previous observations (Gehre et al., 2004). In contrast, the three $\delta^{2} \mathrm{H}-\mathrm{H}_{2} \mathrm{O}$ values below $90^{\circ} \mathrm{C}$ (red diamonds) show an insignificant but slight increase in $\delta^{2} \mathrm{H}-\mathrm{H}_{2} \mathrm{O}$ with septum temperature, which deviated from the pattern above $90^{\circ} \mathrm{C}$. We cannot explain the mismatch between the two patterns above and below $90^{\circ} \mathrm{C}$. We speculate that the initial heating of the septum to temperatures between 70 and $90^{\circ} \mathrm{C}$ caused the desorption of accumulated of $\mathrm{H}_{2} \mathrm{O}$, which was desorbed once the septum was heated to temperatures above $90^{\circ} \mathrm{C}$.

Quantitative conversion of both $\mathrm{CH}_{4}$ and $\mathrm{H}_{2} \mathrm{O}$ in the hightemperature reactor is of utmost importance for our study, because incomplete conversion causes isotopic fractionation in the reaction products (e.g. Burgoyne and Hayes, 1998; Hilkert et al., 1999; Gehre et al., 2004). The reactor temper- 
ature is critical for the efficiency of the conversion process. We performed an experiment with $\mathrm{CH}_{4}$ and $\mathrm{H}_{2} \mathrm{O}$ injections at different reactor temperatures (Fig. A2). For water injections we observe a pronounced, nonlinear $\delta^{2} \mathrm{H}-\mathrm{H}_{2} \mathrm{O}$ change of $\sim 15 \%$ o with reactor temperature increase from 1300 to $1450^{\circ} \mathrm{C}$, reaching a plateau above $1400^{\circ} \mathrm{C}$. The pattern is consistent with previous observations in both trend and magnitude (Gehre et al., 2004). In contrast, the linear fit for $\delta^{2} \mathrm{H}-\mathrm{CH}_{4}$ increases by only about $1 \%$ over the $150{ }^{\circ} \mathrm{C}$ temperature range. However, the slope is statistically insignificant as shown by the $95 \%$ confidence interval of the linear fit (Fig. A2). This analyte-specific isotope variation is also reflected in the areas of the $\mathrm{H}_{2} \mathrm{O}$ and $\mathrm{CH}_{4}$-derived $\mathrm{H}_{2}$ peaks (Fig. A2) (with some significant scatter in the data). While the $\mathrm{H}_{2} \mathrm{O}$-derived $\mathrm{H}_{2}$ peak areas increase with increasing reactor temperature, the $\mathrm{CH}_{4}$-derived $\mathrm{H}_{2}$ peak areas remain constant within the error bars throughout the experiments. For an unknown reason, three out of six $\mathrm{H}_{2}$ peaks that resulted from $\mathrm{H}_{2} \mathrm{O}$ injections at $1400^{\circ} \mathrm{C}$ were by $10-15$ standard deviations smaller than the remaining three peaks. We present the averages and $1 \sigma$ standard of the $\mathrm{H}_{2}$ peaks with and without removal of these outliers in Fig. A2, which shows the exceptional pattern at $1400^{\circ} \mathrm{C}$. Despite this peak size variability, the isotopic composition of all $\mathrm{H}_{2} \mathrm{O}$ injections at $1400^{\circ} \mathrm{C}$ is in good agreement. Our experiments indicate that reactor temperatures in excess of $1400^{\circ} \mathrm{C}$ are required especially for quantitative conversion of $\mathrm{H}_{2} \mathrm{O}$, while the effects of reactor temperature on both yield and the isotopic composition of $\mathrm{CH}_{4}$-derived $\mathrm{H}_{2}$ are comparably small. Therefore, we operate the reactor at a temperature of $1450{ }^{\circ} \mathrm{C}$ to guarantee quantitative conversion without isotope fractionation of both $\mathrm{H}_{2} \mathrm{O}$ (Gehre et al., 2004) and $\mathrm{CH}_{4}$ (Burgoyne and Hayes, 1998; Hilkert et al., 1999). 


\section{The Supplement related to this article is available online at doi:10.5194/amt-9-3717-2016-supplement.}

Acknowledgements. Financial support was provided within the European Commission projects InGOS and IMECC. N. A. M. Uitslag's visit in Jena was made possible by the Erasmus program. Support by Huilin Chen and Harro Meijer (University of Groningen) is gratefully appreciated. We are indebted to Ingeborg Levin for making archived air samples from Neumayer station available for comparison measurements and to Gordon Brailsford and Sara E. Mikaloff Fletcher for valuable comments during the preparation of the manuscript. We are thankful for the insightful reviews of an anonymous reviewer and Ingeborg Levin as well as the comments provided by Sergey Assonov, which altogether helped to improve this paper.

The article processing charges for this open-access publication were covered by the Max Planck Society.

Edited by: F. Keppler

Reviewed by: I. Levin and one anonymous referee

\section{References}

Anicich, V. G.: Evaluated bimolecular ion-molecule gas phase kinetics of positive ions for use in modeling planetary atmospheres, cometary comae, and interstellar clouds, J. Phys. Chem. Ref. Data, 22, 1469-1569, 1993.

Assonov, S. S. and Brenninkmeijer, C. A. M.: A new method to determine the ${ }^{17} \mathrm{O}$ isotopic abundance in $\mathrm{CO}_{2}$ using oxygen isotope exchange with a solid oxide, Rapid Commun. Mass Sp., 15, 2426-2437, 2001.

Behrens, M., Schmitt, J., Richter, K. U., Bock, M., Richter, U. C., Levin, I., and Fischer, H.: A gas chromatography/combustion/isotope ratio mass spectrometry system for high-precision $\delta^{13} \mathrm{C}$ measurements of atmospheric methane extracted from ice core samples, Rapid Commun. Mass Sp., 22, 3261-3269, 2008.

Bergamaschi, P., Schupp, M., and Harris, G. W.: High-precision direct measurements of ${ }^{13} \mathrm{CH}_{4} /{ }^{12} \mathrm{CH}_{4}$ and ${ }^{12} \mathrm{CH}_{3} \mathrm{D} /{ }^{12} \mathrm{CH}_{4}$ ratios in atmospheric methane sources by means of a long-path tunable diode-laser absorption spectrometer, Appl. Optics, 33, 7704-7716, 1994.

Bergamaschi, P., Bräunlich, M., Marik, T., and Brenninkmeijer, C. A. M.: Measurements of the carbon and hydrogen isotopes of atmospheric methane at Izana, Tenerife: Seasonal cycles and synoptic-scale variations, J. Geophys. Res.-Atmos., 105, 1453114546, 2000.

Bock, M., Schmitt, J., Beck, J., Schneider, R., and Fischer, H.: Improving accuracy and precision of ice core $\delta \mathrm{D}\left(\mathrm{CH}_{4}\right)$ analyses using methane pre-pyrolysis and hydrogen post-pyrolysis trapping and subsequent chromatographic separation, Atmos. Meas. Tech., 7, 1999-2012, doi:10.5194/amt-7-1999-2014, 2014.

Brand, W. A., Coplen, T. B., Aerts-Bijma, A. T., Bohlke, J. K., Gehre, M., Geilmann, H., Gröning, M., Jansen, H. G., Meijer,
H. A. J., Mroczkowski, S. J., Qi, H. P., Soergel, K., StuartWilliams, H., Weise, S. M., and Werner, R. A.: Comprehensive inter-laboratory calibration of reference materials for $\delta^{18} \mathrm{O}$ versus VSMOW using various on-line high-temperature conversion techniques, Rapid Commun. Mass Sp., 23, 999-1019, 2009a.

Brand, W. A., Huang, L., Mukai, H., Chivulescu, A., Richter, J. M., and Rothe, M.: How well do we know VPDB? Variability of $\delta^{13} \mathrm{C}$ and $\delta^{18} \mathrm{O}$ in $\mathrm{CO}_{2}$ generated from NBS19-calcite, Rapid Commun. Mass Spectrom., 23, 915-926, 2009b.

Brand, W. A., Coplen, T. B., Vogl, J., Rosner, M., and Prohaska, T.: Assessment of international reference materials for isotoperatio analysis (IUPAC Technical Report), Pure Appl. Chem., 86, 425-467, 2014.

Brand, W. A., Rothe, M., Sperlich, P., Strube, M., and Wendeberg, M.: Automated simultaneous measurement of the $\delta^{13} \mathrm{C}$ and $\delta^{2} \mathrm{H}$ values of methane and the $\delta^{13} \mathrm{C}$ and $\delta^{18} \mathrm{O}$ values of carbon dioxide in flask air samples using a newmulti cryo-trap/gas chromatography/isotope ratio mass spectrometry system, Rapid Commun. Mass Sp., 30, 1523-1539, 2016.

Brass, M. and Röckmann, T.: Continuous-flow isotope ratio mass spectrometry method for carbon and hydrogen isotope measurements on atmospheric methane, Atmos. Meas. Tech., 3, 17071721, doi:10.5194/amt-3-1707-2010, 2010.

Bräunlich, M., Aballanin, O., Marik, T., Jockel, P., Brenninkmeijer, C. A. M., Chappellaz, J., Barnola, J. M., Mulvaney, R., and Sturges, W. T.: Changes in the global atmospheric methane budget over the last decades inferred from ${ }^{13} \mathrm{C}$ and $\mathrm{D}$ isotopic analysis of Antarctic firn air, J. Geophys. Res.-Atmos., 106, 20465 20481, 2001.

Brooks, P. D., Geilmann, H., Werner, R. A., and Brand, W. A.: Improved precision of coupled $\delta^{13} \mathrm{C}$ and $\delta^{15} \mathrm{~N}$ measurements from single samples using an elemental analyser/isotope ratio mass spectrometer combination with a post-column six-port valve and selective $\mathrm{CO}_{2}$ trapping; improved halide robustness of the combustion reactor using $\mathrm{CeO}_{2}$, Rapid Commun. Mass Sp., 17, 1924-1926, 2003.

Brunnée, C. and Voshage, H.: Massenspektrometrie, Teil 1, Verlag Karl Thiemig KG, München, 12 edition, 1964.

Burgoyne, T. W. and Hayes, J. M.: Quantitative production of $\mathrm{H}_{2}$ by pyrolysis of gas chromatographic effluents, Anal. Chem., 70, 5136-5141, 1998.

Coplen, T. B., Brand, W. A., Gehre, M., Gröning, M., Meijer, H. A. J., Toman, B., and Verkouteren, R. M.: After two decades a second anchor for the VPDB $\delta^{13} \mathrm{C}$ scale, Rapid Commun. Mass Sp., 20, 3165-3166, 2006a.

Coplen, T. B., Brand, W. A., Gehre, M., Gröning, M., Meijer, H. A. J., Toman, B., and Verkouteren, R. M.: New guidelines for $\delta^{13} \mathrm{C}$ measurements, Anal. Chem., 78, 2439-2441, 2006 b.

Craig, H.: The Geochemistry of the Stable Carbon Isotopes, Geochim. Cosmochim. Acta, 3, 53-92, 1953.

Dumke, I., Faber, E., and Poggenburg, J.: Determination of Stable Carbon and Hydrogen Isotopes of Light Hydrocarbons, Anal Chem., 61, 2149-2154, 1989.

Eyer, S., Tuzson, B., Popa, M. E., van der Veen, C., Röckmann, T., Rothe, M., Brand, W. A., Fisher, R., Lowry, D., Nisbet, E. G., Brennwald, M. S., Harris, E., Zellweger, C., Emmenegger, L., Fischer, H., and Mohn, J.: Real-time analysis of $\delta^{13} \mathrm{C}$ - and $\delta \mathrm{D}$ $\mathrm{CH}_{4}$ in ambient air with laser spectroscopy: method development 
and first intercomparison results, Atmos. Meas. Tech., 9, 263280, doi:10.5194/amt-9-263-2016, 2016.

Friedman, I.: Deuterium content of natural waters and other substances, Geochim. Cosmochim. Ac., 4, 89-103, 1953.

Gehre, M., Geilmann, H., Richter, J., Werner, R. A., and Brand, W. A.: Continuous flow ${ }^{2} \mathrm{H} /{ }^{1} \mathrm{H}$ and and ${ }^{18} \mathrm{O} /{ }^{16} \mathrm{O}$ analysis of water samples with dual inlet precision, Rapid Commun. Mass Sp., 18, 2650-2660, 2004.

Ghosh, P., Patecki, M., Rothe, M., and Brand, W. A.: Calcite- $\mathrm{CO}_{2}$ mixed into $\mathrm{CO}_{2}$-free air: a new $\mathrm{CO}_{2}$-in-air stable isotope reference material for the VPDB scale, Rapid Commun. Mass Spectrom., 19, 1097-1119, 2005.

Gröning, M., Van Duren, M., and Andreescu, L.: Metrological characteristics of the conventional measurement scales for hydrogen and oxygen stable isotope amount ratios: the $\delta$-scales, in: Combining and Reporting Analytical Results, edited by: Fajgelj, A., Belli, M., Sansone, U., Proceedings of an International Workshop on "Combining and reporting analytical results: The role of traceability and uncertainty for comparing analytical results", Rome, 6-8 March 2006, Royal Society of Chemistry, 62-72, 2007.

Hilkert, A. W., Douthitt, C. B., Schlüter, H. J., and Brand, W. A.: Isotope ratio monitoring gas chromatography/mass spectrometry of $\mathrm{D} / \mathrm{H}$ by high temperature conversion isotope ratio mass spectrometry, Rapid Commun. Mass Sp., 13, 1226-1230, 1999.

IAEA: Development and use of reference materials and quality control materials, IAEA TecDoc 1350, International Atomic Energy Agency, 113 pp., 2003.

Kai, F. M., Tyler, S. C., Randerson, J. T., and Blake, D. R.: Reduced methane growth rate explained by decreased Northern Hemisphere microbial sources, Nature, 476, 194-197, 2011.

Levin, I., Veidt, C., Vaughn, B. H., Brailsford, G., Bromley, T., Heinz, R., Lowe, D., Miller, J. B., Poss, C., and White, J. W. C.: No inter-hemispheric $\delta^{13} \mathrm{CH}_{4}$ trend observed, Nature, 486, E3-E4, 2012.

Lowe, D. C., Brenninkmeijer, C. A. M., Brailsford, G. W., Lassey, K. R., Gomez, A. J., and Nisbet, E. G.: Concentration and ${ }^{13} \mathrm{C}$ records of atmospheric methane in New Zealand and Antarctica - Evidence for changes in methane sources, J. Geophys. Res.Atmos., 99, 16913-16925, 1994.

Merritt, D. A., Freeman, K. H., Ricci, M. P., Studley, S. A., and Hayes, J. M.: Performance and optimization of a combustion interface for isotope ratio monitoring gas-chromatography massspectrometry, Anal. Chem., 67, 2461-2473, 1995.

Mikaloff Fletcher, S. E., Tans, P. P., Bruhwiler, L. M., Miller, J. B., and Heimann, M.: $\mathrm{CH}_{4}$ sources estimated from atmospheric observations of $\mathrm{CH}_{4}$ and its ${ }^{13} \mathrm{C} /{ }^{12} \mathrm{C}$ isotopic ratios: 1 . Inverse modeling of source processes, Global Biogeochem. Cy., 18, GB4004, doi:10.1029/2004GB002223, 2004.

Möller, L., Sowers, T., Bock, M., Spahni, R., Behrens, M., Schmitt, J., Miller, H., and Fischer, H.: Independent variations of $\mathrm{CH}_{4}$ emissions and isotopic composition over the past 160,000 years, Nat. Geosci., 6, 885-890, 2013.

Qi, H. P., Coplen, T. B., Mroczkowski, S. J., Brand, W. A., Brandes, L., Geilmann, H., and Schimmelmann, A.: A new organic refer-

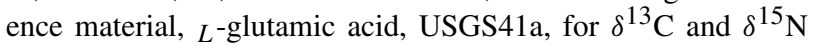
measurements - a replacement for USGS41, Rapid Commun. Mass Sp., 30, 859-866, 2016.
Quay, P. D., King, S. L., Stutsman, J., Wilbur, D. O., Steele, L. P., Fung, I., Gammon, R. H., Brown, T. A., Farwell, G. W., Grootes, P. M., and Schmidt, F. H.: Carbon isotopic composition of atmospheric $\mathrm{CH}_{4}$ : Fossil and biomass burning source strengths, Global Biogeochem. Cy., 5, 25-48, 1991.

Quay, P., Stutsman, J., Wilbur, D., Snover, A., Dlugokencky, E., and Brown, T.: The isotopic composition of atmospheric methane, Global Biogeochem. Cy., 13, 445-461, 1999.

Rella, C. W., Hoffnagle, J., He, Y., and Tajima, S.: Local- and regional-scale measurements of $\mathrm{CH}_{4}, \delta^{13} \mathrm{CH}_{4}$, and $\mathrm{C}_{2} \mathrm{H}_{6}$ in the Uintah Basin using a mobile stable isotope analyzer, Atmos. Meas. Tech., 8, 4539-4559, doi:10.5194/amt-8-4539-2015, 2015.

Röckmann, T., Eyer, S., van der Veen, C., Popa, M. E., Tuzson, B., Monteil, G., Houweling, S., Harris, E., Brunner, D., Fischer, H., Zazzeri, G., Lowry, D., Nisbet, E. G., Brand, W. A., Necki, J. M., Emmenegger, L., and Mohn, J.: In-situ observations of the isotopic composition of methane at the Cabauw tall tower site, Atmos. Chem. Phys. Discuss., doi:10.5194/acp-2016-60, in review, 2016.

Sapart, C. J., van der Veen, C., Vigano, I., Brass,, M., van de Wal, R. S. W., Bock, M., Fischer, H., Sowers, T., Buizert, C., Sperlich, P., Blunier, T., Behrens, M., Schmitt, J., Seth, B., and Röckmann, T.: Simultaneous stable isotope analysis of methane and nitrous oxide on ice core samples, Atmos. Meas. Tech., 4, 2607-2618, doi:10.5194/amt-4-2607-2011, 2011.

Sapart, C. J., Monteil, G., Prokopiou, M., van de Wal, R. S. W., Kaplan, J. O., Sperlich, P., Krumhardt, K. M., van der Veen, C., Houweling, S., Krol, M. C., Blunier, T., Sowers, T., Martinerie, P., Witrant, E., Dahl-Jensen, D., and Röckmann, T.: Natural and anthropogenic variations in methane sources during the past two millennia, Nature, 490, 85-88, 2012.

Sapart, C. J., Martinerie, P., Witrant, E., Chappellaz, J., van de Wal, R. S. W., Sperlich, P., van der Veen, C., Bernard, S., Sturges, W. T., Blunier, T., Schwander, J., Etheridge, D., and Röckmann, T.: Can the carbon isotopic composition of methane be reconstructed from multi-site firn air measurements?, Atmos. Chem. Phys., 13, 6993-7005, doi:10.5194/acp-13-6993-2013, 2013.

Schaefer, H., Fletcher, S. E. M., Veidt, C., Lassey, K. R., Brailsford, G. W., Bromley, T. M., Dlugokencky, E. J., Michel, S. E., Miller, J. B., Levin, I., Lowe, D. C., Martin, R. J., Vaughn, B. H., and White, J. W. C.: A 21st-century shift from fossil-fuel to biogenic methane emissions indicated by ${ }^{13} \mathrm{CH}_{4}$, Science, 352 , 80-84, 2016.

Schiegl, W. E. and Vogel, J. C.: Deuterium Content of Organic Matter, Earth Planet. Sc. Lett., 7, 307-313, 1970.

Schimmelmann, A., Qi, H. P., Coplen, T. B., Brand, W. A., Fong, J., Meier-Augenstein, W., Kemp, H. F., Toman, B., Ackermann, A., Assonov, S., Aerts-Bijma, A. T., Brejcha, R., Chikaraishi, Y., Darwish, T., Elsner, M., Gehre, M., Geilmann, H., Gröning, M., Helie, J. F., Herrero-Martin, S., Meijer, H. A. J., Sauer, P. E., Sessions, A. L., and Werner, R. A.: Organic Reference Materials for Hydrogen, Carbon, and Nitrogen Stable Isotope-Ratio Measurements: Caffeines, n-Alkanes, Fatty Acid Methyl Esters, Glycines, L-Valines, Polyethylenes, and Oils, Anal. Chem., 88, 4294-4302, 2016.

Schmitt, J., Seth, B., Bock, M., van der Veen, C., Möller, L., Sapart, C. J., Prokopiou, M., Sowers, T., Röckmann, T., and Fischer, H.: On the interference of $\mathrm{Kr}$ during carbon isotope 
analysis of methane using continuous-flow combustion-isotope ratio mass spectrometry, Atmos. Meas. Tech., 6, 1425-1445, doi:10.5194/amt-6-1425-2013, 2013.

Schmitt, J., Seth, B., Bock, M., and Fischer, H.: Online technique for isotope and mixing ratios of $\mathrm{CH}_{4}, \mathrm{~N}_{2} \mathrm{O}$, Xe and mixing ratios of organic trace gases on a single ice core sample, Atmos. Meas. Tech., 7, 2645-2665, doi:10.5194/amt-7-2645-2014, 2014.

Sessions, A. L., Burgoyne, T. W., and Hayes, J. M.: Determination of the $\mathrm{H}_{3}$ factor in hydrogen isotope ratio monitoring mass spectrometry, Anal. Chem., 73, 200-207, 2001.

Sperlich, P., Guillevic, M., Buizert, C., Jenk, T. M., Sapart, C. J., Schaefer, H., Popp, T. J., and Blunier, T.: A combustion setup to precisely reference $\delta^{13} \mathrm{C}$ and $\delta^{2} \mathrm{H}$ isotope ratios of pure $\mathrm{CH} 4$ to produce isotope reference gases of $\delta^{13} \mathrm{C}^{-} \mathrm{CH}_{4}$ in synthetic air, Atmos. Meas. Tech., 5, 2227-2236, doi:10.5194/amt-5-2227-2012, 2012.

Sperlich, P., Buizert, C., Jenk, T. M., Sapart, C. J., Prokopiou, M., Röckmann, T., and Blunier, T.: An automated GC-C-GC-IRMS setup to measure palaeoatmospheric $\delta^{13} \mathrm{C}_{-} \mathrm{CH}_{4}, \delta^{15} \mathrm{~N}-\mathrm{N}_{2} \mathrm{O}$ and $\delta^{18} \mathrm{O}-\mathrm{N}_{2} \mathrm{O}$ in one ice core sample, Atmos. Meas. Tech., 6, 20272041, doi:10.5194/amt-6-2027-2013, 2013.

Sperlich, P., Schaefer, H., Mikaloff Fletcher, S. E., Guillevic, M., Lassey, K. R., Sapart, C. J., Röckmann, T., and Blunier, T.: Carbon isotope ratios suggest no additional methane from boreal wetlands during the rapid Greenland Interstadial 21.2, Global Biogeochem. Cy., 29, 1962-1976, 2015.

Stevens, C. M. and Rust, F. E.: The Carbon Isotopic Composition of Atmospheric Methane, J. Geophys. Res.-Oceans, 87, 48794882, 1982.
Tokida, T., Nakajima, Y., Hayashi, K., Usui, Y., Katayanagi, N., Kajiura, M., Nakamura, H., and Hasegawa, T.: Fully automated, high-throughput instrumentation for measuring the $\delta^{13} \mathrm{C}$ value of methane and application of the instrumentation to rice paddy samples, Rapid Commun. Mass Sp., 28, 2315-2324, 2014.

Verkouteren, R. M. and Klinedinst, D. B.: Value Assignment and Uncertainty Estimation of Selected Light Stable Isotope Reference Materials: RMs 8543-8545, RMs 8562-8564, and RM 8566, Natl. Inst. Stand. Technol. Spec. Publ. 260-149 2004 ED, 58 pp., 2004.

Wendeberg, M., Richter, J. M., Rothe, M., and Brand, W. A.: Jena Reference Air Set (JRAS): a multi-point scale anchor for isotope measurements of $\mathrm{CO} 2$ in air, Atmos. Meas. Tech., 6, 817-822, doi:10.5194/amt-6-817-2013, 2013.

Werner, R. A. and Brand, W. A.: Referencing strategies and techniques in stable isotope ratio analysis, Rapid Commun. Mass Spectrom., 15, 501-519, 2001.

Werner, R. A., Bruch, B. A., and Brand, W. A.: ConFlo III - An interface for high precision $\delta^{13} \mathrm{C}$ and $\delta^{15} \mathrm{~N}$ analysis with an extended dynamic range, Rapid Commun. Mass Sp., 13, 12371241, 1999.

WMO: Report of the 16th WMO/IAEA Meeting on Carbon Dioxide, Other Greenhouse Gases, and Related Measurement Techniques (GGMT-2011), edited by: Brailsford, G., GAW Report 206, Wellington, New Zealand, 2012.

WMO: Report of the 17th WMO/IAEA Meeting on Carbon Dioxide, Other Greenhouse Gases, and Related Measurement Techniques (GGMT-2011), edited by: Tans, P. and Zellweger, C., GAW Report 213, Beijing, China, 2014. 